\title{
Seismicity in far western Nepal reveals flats and ramps along the Main Himalayan Thrust
}

\author{
M. Laporte ${ }^{\oplus},{ }^{1,2}$ L. Bollinger,${ }^{1}$ H. Lyon-Caen, ${ }^{2}$ R. Hoste-Colomer, ${ }^{3}$ C. Duverger,${ }^{1}$ \\ J. Letort, ${ }^{4}$ M. Riesner, ${ }^{1}$ B. P. Koirala, ${ }^{5}$ M. Bhattarai, ${ }^{5}$ T. Kandel,${ }^{5}$ C. Timsina ${ }^{5}$ and L. \\ B. Adhikari ${ }^{5}$ \\ ${ }^{1}$ CEA, DAM, DIF, F-91297 Arpajon, France.E-mail: marine.laporte@cea.fr \\ ${ }^{2}$ Laboratoire de Géologie - CNRS UMR 8538, Ecole normale supérieure - PSL University, 75005 Paris, France \\ ${ }^{3}$ French Geological Survey, Direction Risques et Prévention, 3, av. C. Guillemin, 45060 Orléans, France \\ ${ }^{4}$ Observatoire Midi Pyrénées, IRAP, CNRS UMR 5277, Université Paul Sabatier, Toulouse, France \\ ${ }^{5}$ Department of Mines and Geology, Nepalese National Earthquake Monitoring and Research Centre, Lainchaur, Kathmandu, Nepal
}

Accepted 2021 0. Received 2021 April 12; in original form 2020 December 14

\begin{abstract}
SUMMAR Y
Unravelling relations between lateral variations of mid-crustal seismicity and the geometry of the Main Himalayan Thrust (MHT) system at depth is a key issue in seismotectonic studies of the Himalayan range. These relations can reveal along strike changes in the behaviour of the fault at depth related to fluids or the local ramp-flat geometry and more generally of the stress build-up along the fault. Some of these variations may control the rupture extension of intermediate, large or great earthquakes, the last of which dates back from $1505 \mathrm{CE}$ in far western Nepal. The region is also associated to lateral spatio-temporal variations of the midcrustal seismicity monitored by the Regional Seismic Network of Surkhet-Birendranagar. This network was supplemented between 2014 and 2016 by 15 temporary stations deployed above the main seismic clusters giving new potential to regional studies. Both absolute and relative locations together with focal mechanisms are determined to gain insight on the fault behaviour at depth. We find more than 4000 earthquakes within 5 and $20 \mathrm{~km}$-depth clustered in three belts parallel to the front of the Himalayan range. Finest locations reveal close relationships between seismic clusters and fault segments at depth among which mid-crustal ramps and reactivated tectonic slivers. Our results support a geometry of the MHT involving several fault patches at depth separated by ramps and tear faults. This geometry most probably affects the pattern of the coseismic ruptures breaking partially or totally the locked fault zone as well as eventual along strike variations of seismic coupling during interseismic period.
\end{abstract}

Key words: Seismicity and tectonics; Seismic cycle; Crustal structure; Asia.

\section{INTRODUCTION}

Most of the continental or oceanic subductions megathrust systems produce large and great earthquakes resulting from the release of decades to centuries of stress build-up (e.g Bürgmann et al. 2005; Avouac 2015; Herman et al. 2018). These active fault systems also frequently produce small and moderate size earthquakes, which generally occur along the downdip edge of the interseismic locked zone. Despite promising associations between earthquake swarms and reduced plate coupling (e.g. Holtkamp \& Brudinski 2014), no simple relations exist between the seismicity and the coupling coefficient (e.g. Tichelaar \& Ruff 1993; Métois et al. 2016). However, small earthquakes are often related to stress or fluid transfer in the crust and their occurrence is influenced by structures at depth acting as potential receiver faults for stress build-up, barriers or conduits (e.g. Holtkamp \& Brudzinski 2014; Ross et al. 2020). The along strike and temporal variations of small earthquakes is therefore promising for determining the morphology of the fault system, a parameter controlling the behaviour and extension of the seismic rupture (e.g. Qiu et al. 2016; Sippl et al. 2018).

In Nepal, the Main Himalayan Thrust (MHT), the plate boundary fault between India and the Himalayas, produces infrequent large (M7) and great (M8+) devastating earthquakes rupturing the locked zone up to the surface. More frequently, the MHT produces as well mid-crustal seismic clusters organized in a belt of seismicity that roughly follows the Himalayan topographic front (e.g. Pandey et al. 1995; Cattin \& Avouac 2000; Bollinger et al. 2004; Ader et al. 2012). The density of these local earthquakes recorded at the Nepalese seismological network during the $20 \mathrm{yr}$ that preceded the $2015 M_{\mathrm{w}} 7.9$ Gorkha earthquake, depicts some significant 
lateral variations of the mid-crustal seismicity (Fig. 1). Segments of the seismicity belt are marked by dense clusters, particularly in central and eastern Nepal while others, in mid-western Nepal, are less expressed. In eastern Nepal, the seismicity is distributed over a large area, the region being affected by both mid-crustal earthquakes on the MHT and deep earthquakes affecting the subducting plate (Monsalve et al. 2006). Finally, in far western Nepal, the mid-crustal seismicity is divided in segments outlining two dense seismic belts whose northern-end mimics the embayment of topography.

The belt of seismicity which develops at mid-crustal depths in central Nepal coincides with the downdip-end of a locked portion of the MHT (e.g. Bollinger et al. 2004; Ader et al. 2012 ) that falls in the vicinity of a mid-crustal ramp (e.g. Pandey et al. 1995; Cattin \& Avouac 2000; Grandin et al. 2015).

Indeed, a flat-ramp-flat geometry of the MHT was deduced from the subsurface geology and long-term uplift (e.g. Schelling \& Arita 1991; Lavé \& Avouac 2000; DeCelles et al. 2001; Robinson et al. 2006; Hubbard et al. 2016). This structure is difficult to resolve along strike with geophysical images, which mainly documented the major flat decollements (Schulte-Pelkum et al. 2005; Nabelek et al. 2009). However, the multidisciplinary researches conducted after the $2015 M_{\mathrm{w}} 7.8$ Gorkha earthquake in Nepal, involving dense seismological arrays, geology and geodesy (e.g. Adhikari et al. 2015; Avouac 2015; Grandin et al. 2015; Hubbard et al. 2016; Baillard et al. 2017; Bai et al. 2019; Kurashimo et al. 2019; Mendoza et al. 2019; Karplus et al. 2020; Yamada et al. 2020, Wang et al. 2017) demonstrated the presence and the role of midcrustal structures that controlled both the coseismic rupture and the aftershocks distribution. Recent deployments of dense seismological networks elsewhere above active fault segments provide enhanced resolutions of earthquake hypocentres and the capacity to discuss eventual relations between the midcrustal seismicity and structures (e.g. Acton et al. 2011; Diehl et al. 2017; Hoste-Colomer et al. 2018).

Here we describe the characteristics of the Himalayan-Karnali Network (HiKNet), the first dense seismological network deployed between 2014 and 2016 above the seismicity of far western Nepal (Fig. 1). The goal of this temporary experiment was to resolve the spatiotemporal distribution of seismic clusters in this region where multiple ramps are suspected and may control the coseismic ruptures (e.g. Pandey et al. 1995; Harvey et al. 2015; Hoste-Colomer et al. 2018; Lindsey et al. 2018). This article specifically complements a previous study focused on the first year of acquisition (HosteColomer et al. 2018). We review the location procedures and complement the catalogue of earthquakes which comprises 4500 events. High quality locations and focal mechanisms are confronted to geophysical imagery (Subedi et al. 2018) and balanced cross-sections (Robinson et al. 2006) in order to describe the behaviour of the seismicity and its lateral heterogeneities in relation with the geological structures.

\section{DATA ACQUISITION AND METHODOLOGY}

\subsection{Data acquisition}

Our analysis relies on 2-yr of data recovery from the temporary seismic experiment HiKNet (Himalayan-Karnali network) deployed in far western Nepal from November 2014 to September 2016. This temporary network of 15 seismographs has supplemented the permanent seismological network maintained by the Regional Seismic
Center (RSC) of Surkhet-Birendranagar. During the time of the experiment, the RSC network consisted of 8 short-period vertical seismometers and one 3-components broad-band seismometer (BHMN) sampling at $50 \mathrm{~Hz}$ and located several kilometers away from the seismicity (Hoste-Colomer et al. 2018). Due to the lack of horizontal components for picking $S$-wave arrivals, RSC computes epicentral locations of earthquakes fixing their depth at 2, 10, 25 or $50 \mathrm{~km}$. The temporary network was composed by 3 -components instruments including 8 broad-band seismometers and 7 short-period seismometers provided by the French mobile instruments RESIFSISMOB. All stations were associated with a digitizer sampling at $100 \mathrm{~Hz}$ connected to a Global Positioning System antenna for real-time synchronization (Table $\mathrm{S} 1$ ).

The temporary network was designed to record far western Nepal seismicity. Temporary stations have been installed above three seismic belts referred hereafter as the Bajhang (BAJ), North-Karnali (NK) and South-Karnali (SK) seismic belts (Fig. 1). They allow to extend the regional network to the north and to improve its capacity at determining accurate hypocentral locations for regional seismicity. Inter-stations distances were defined in accordance with the expected depth of the seismicity from 10 to $20 \mathrm{~km}$ (Hoste-Colomer et al. 2018).

The network capacity to record earthquakes could also be affected by the increase of high frequency seismic noise during monsoon periods, due to rivers and landslides (e.g. Burtin et al. 2007; Burtin et al. 2009). Out of the 24 seismological instruments, 9 were off during the 2015 monsoon, resulting in a lower number of located earthquakes between May and September 2015 (Fig. 2). During the second half of the experiment, only two stations (GH25 and KS11) had recording problems. Raw seismic data from HiKNet stations are in open access through RESIF web-service (https://doi.org/10.1 5778/RESIF.ZO2014).

\subsection{Earthquake location and quality assessment}

Earthquakes are located following: (1) an automatic detection and preliminary method using Seiscomp3 monitoring software (Weber et al. 2007); (2) an Hypo71 location (Lee \& Lahr 1972) after manually reviewing and weighting phase arrivals and (3) a relative relocation using the double difference HypoDD approach (Waldhauser \& Ellsworth 2000) on the phase picks.

Automatic detections are first performed through the Seiscomp3 software following the workflow used in Hoste-Colomer et al. 2018. A trigger STA/LTA with respective windows of 1 and $10 \mathrm{~s}$ is used for automatic detections of $P$ onsets. $S$ onsets are detected within a $20 \mathrm{~s}$ window after the onset of each $P$-wave arrivals with the same trigger ratios. Both $P$ and $S$ detections are refined according to the Akaike's Information Criterion (AIC) filter (Akaike 2011).

Since time-arrivals biases and false detections are expected to be introduced by the automatic procedure, we refined manually every onset of $P$ and $S$ phase arrivals. False arrivals generated by high seismic noise, teleseismic events and earthquakes from the Gorkha aftershocks sequence are discarded during this step. Out of 12700 events detected automatically, 6590 events were located outside the network $\left(80.3-82.5^{\circ} \mathrm{E} / 28.3-30.2^{\circ} \mathrm{N}\right)$ and 1615 were false detections or events described by loose association of picks. Weighting picks observations is the most common way to reduce uncertainties on measurement of arrival times (Buland 1976). The manually picked phases are weighted following the Hypo 71 nomenclature, between 0 (high quality) and 3 (high uncertainty) according to our assessment of uncertainty on phase arrivals. 


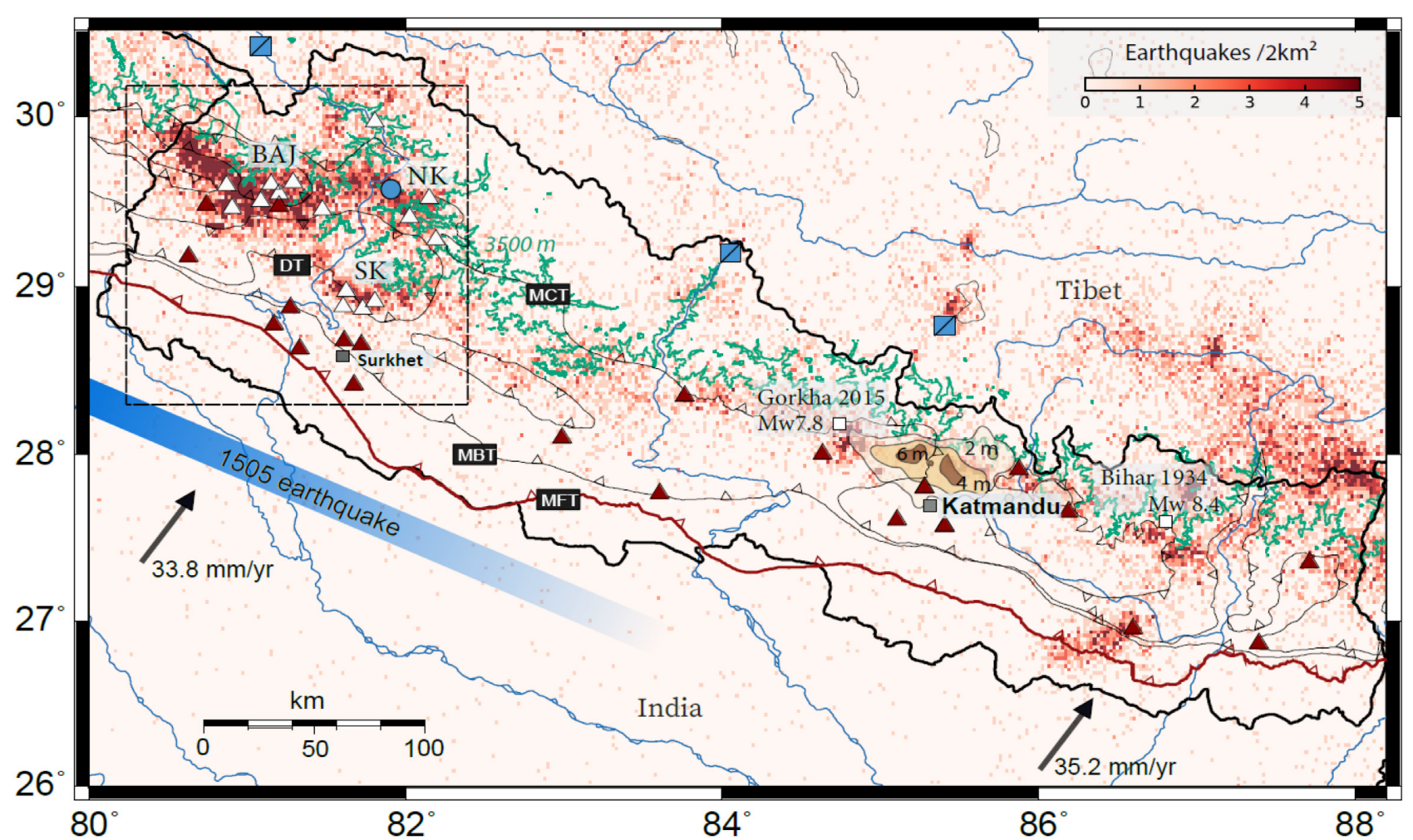

Figure 1. Density of earthquakes per $2 \mathrm{~km}^{2}$ recorded by the national and regional Nepalese seismological centres from 1994 to 2014 . Main thrust faults and tectonic features are represented: the Main Frontal Thrust as a bold red line and secondary thrusts faults as black lines upfront. Main Himalayan Rivers are in blue and the iso-altitude $3500 \mathrm{~m}$ in green. The blue bar locates the suspected extension of the great 1505 earthquake (Bilham et al. 2001). Blue squares locate the location of three prime witnesses of the 1505 event consequence (Bollinger et al. 2014) and the blue circle locates the Rara lake where turbidites associated to the 1505 earthquake have been recently evidenced (Ghazoui et al. 2019). Red and white triangles represent the permanent RSC and temporary HIKNET seismological networks, respectively. White squares correspond to epicentres of the largest instrumental earthquakes from the last century. Velocity and direction of the Indian plate displacement are also represented as black arrows (Bettinelli et al. 2006). Isocontours of the 2015 Gorkha earthquake coseismic slip are also added north of Kathmandu (Grandin et al. 2015). Faults: MFT = Main Frontal Thrust, MBT = Main Boundary Thrust, MCT = Main Central Thrust, DT = Dadeldhura klippe. Zones of interests: NK = North Karnali, SK = South Karnali, BAJ = Bajhang.

Locations are performed through Hypo 71 algorithm (Lee \& Lahr 1972) taking into account a regional velocity model (Pandey 1985). The uncertainties on the hypocentral locations due to the velocity model are reduced by weighting the picks as a function of the epicentral distance. This location procedure gives a final robust catalogue of 4447 events.

The three layers velocity model constrained by Pandey (1985) for central Nepal has been considered appropriate for far western Nepal, following a VELEST (Kissling et al. 1995) joint inversion of 1-Dvelocity model and hypocentral parameters from 340 earthquakes recorded by the HiKNet network (Benoit 2016).

Empirically, events with horizontal and vertical standard errors lower than $2 \mathrm{~km}$, absolute traveltime residual lower than $0.4 \mathrm{~s}$ and having at least 6 P-picks and 3 S-picks are considered as highquality events (Figs 3A-E). 2302 events (52 per cent of the whole catalogue) satisfy these selection criteria, most of them are clustered inside the three distinct zones BAJ, NK and SK.

We compared this catalogue of 'best located hypocentres' with the seismic catalogue produced by the seismic analysts working on the permanent RSC network. 1050 events were common to both catalogues. We find an average epicentral offset of $7 \mathrm{~km}$ inside the three zones well-covered by temporary stations, the larger the distance, the larger the offset. In addition, an azimuthal bias in RSC locations varying between N315E and N045E from west to east is highlighted (Fig. S1).
In order to refine the relative location of earthquakes within the clusters, we applied the double difference location algorithm HypoDD (Waldhauser \& Ellsworth 2000) on high quality events. The double difference method uses traveltime differences between pairs of events estimated from the catalogue of manual picks.

We find an optimal setting of events pairing by fixing a maximum distance of $100 \mathrm{~km}$ between a pair of events and a station, $10 \mathrm{~km}$ between events constituting a pair. Each pair is defined by a maximum number of 10 neighbors per event, a minimum of 8 links and 8 phase's observations. From 2302 high quality events composed of 40303 phases, we found 123031 pairs of $P$ phases and 74768 pairs of $S$-phases constituting 15160 pairs of events with an average number of 12 links and an average offset between event's pairs of $2.2 \mathrm{~km}$.

The double difference relocation process follows a three round iteration, beginning with five iterations considering only differences in $P$-phases arrival times, and then five iterations considering both $P$-phases and $S$-phases arrivals. Finally, the last round is composed of ten iterations with both phases but we add a threshold of $8 \mathrm{~ms}$ between relative differences and a maximum distance of $6 \mathrm{~km}$ between pairs. Since we have a large data set, the least square solution is computed from the conjugate gradient routine of HypoDD (Waldhauser \& Ellsworth 2000). From the selection of 147029 pairs of $P$ and $S$ phases, we get relative locations of 2151 events. 


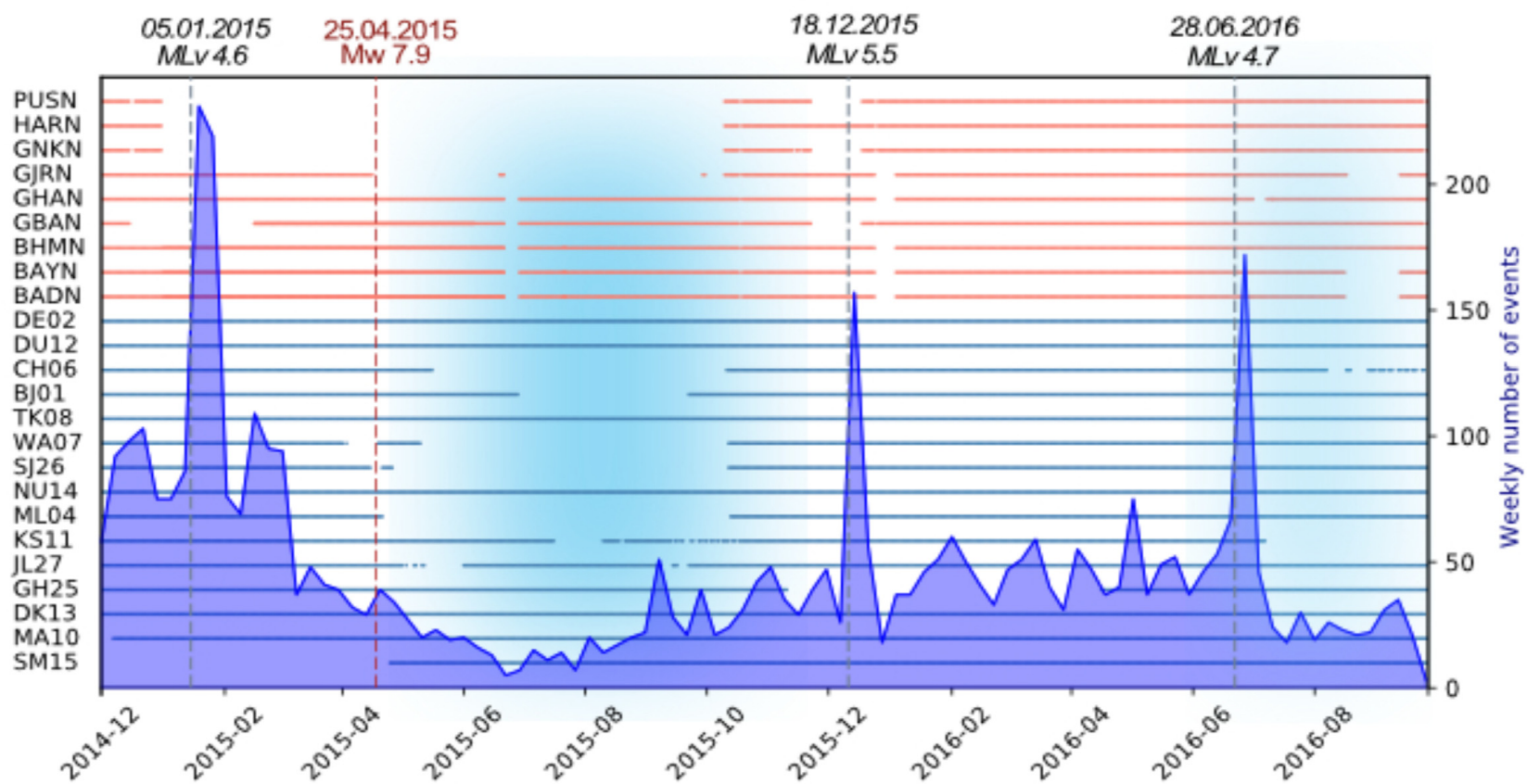

Figure 2. Data availability of HiKNet temporary stations (Network ZO) and RSC permanent stations (Network N) from December 2014 to November 2016 represented as blue and red horizontal lines, respectively. Time-distribution of earthquakes is represented as the dark-blue curve. Periods of monsoon are represented as blue shaded time-spans.

Full catalogues of absolute and relative relocations are provided in digital form in the Supplementary Data materials.

\subsection{Magnitude determination and analysis}

A local magnitude $M_{\mathrm{Lv}}$ is evaluated at each station from the maximum amplitude of the vertical component in a time window around the $P$ arrival and taking into account the widely used attenuation function defined for California by Richter (1935).

$M_{\mathrm{Lv}}$ can then be converted into the local magnitude $M_{\mathrm{L}}$ determined by the Nepalese analysts (Fig. S2), following:

$M_{\mathrm{L}}=0.87 M_{\mathrm{Lv}}+0.92$

The two magnitudes are offset by 0.7 on average (Fig. S3). The magnitude of completeness $M_{\mathrm{c}}$ for the catalogue of events that occurred below the network during the entire time span of the regional experiment is estimated at $M_{\mathrm{LV}} 1.3$. The $b$-value is estimated at 0.77 \pm 0.02 (Fig. 4b). For the same time span, the magnitude of completeness of the RSC network is estimated at $M_{\mathrm{Lv}} 1.8$ with a $b$-value of $0.76 \pm 0.02$ (Fig. 4a).

Moment magnitudes $M_{\mathrm{w}}$ used for the cumulative moment determination were obtained using the SourceSpec algorithm (Satriano 2020). The algorithm inverts the $S$-wave displacement spectra which are modelled as the product of a source term considering a Brune model and a propagation term considering a geometric and anelastic attenuation of the body waves. The seismic moment, the corner frequency and the attenuation are considered as unknown parameters in the inversion and iterated following a LevenbergMarquardt algorithm. The relation between $M_{\mathrm{w}}$ and $M_{\mathrm{Lv}}$ depicts a break in slope that we compare to the three-step scaling relation proposed for Switzerland (Goertz-Allman et al. 2011, Fig. $\mathrm{S} 4)$. This scaling relation in three steps was proposed in order to compensate for a probable bias in $M_{\mathrm{Lv}}$ determination for smaller magnitudes.

\subsection{Focal mechanisms}

We selected nine moderate-size earthquakes $\left(M_{\mathrm{Lv}} \geq 3.5\right)$ with high quality locations and a minimum of eight polarities from the $P$-wave first arrivals, covering the whole focal sphere.

Three of these events belong to the seismic sequence of the 26 June $2016 M_{\mathrm{Lv}} 4.7$ earthquake, a sequence for which we estimate one additional focal mechanism associated to an event of magnitude $M_{\mathrm{Lv}} 3.1$ with high quality location and impulsive polarities. To complete our study, we use a solution from the GCMT database for the 18 December 2015 earthquake of magnitude $M_{\mathrm{Lv}} 5.5$ (Dziewonski et al. 1981; Ekström et al. 2012) since our stations were too far from the hypocentre to constrain properly the focal sphere.

We assign to each polarity a weight from 0 to 4 depending on firsthand level of confidence, 0 corresponding to a clear and impulsive first motion, 1 to a clear however emergent first-motion and then increasing with the decrease in confidence.

FPFIT program (Reasenberg 1985) determines the best double couple fault plane solution from each set of weighted first motion polarities (Table 1). This grid-search algorithm, scanning the focal mechanism parameters (strike, dip and rake), finds the optimal fit between the observed and computed polarities, considering manual weights from polarity confidence and giving a greater weight for observations near the nodal planes. Eventually, the program proposes alternative solutions corresponding to local minima in the misfit function.

We chose to use first motion polarities in regards to the rather small sizes of the seismic sources $\left(\mathrm{M}_{\mathrm{Lv}}\right.$ from 3.2 to 4.7 or $\mathrm{M}_{\mathrm{w}}$ below 4.2). A regional inversion of these focal mechanisms requires modelling the long-period regional waveforms in a relatively high 

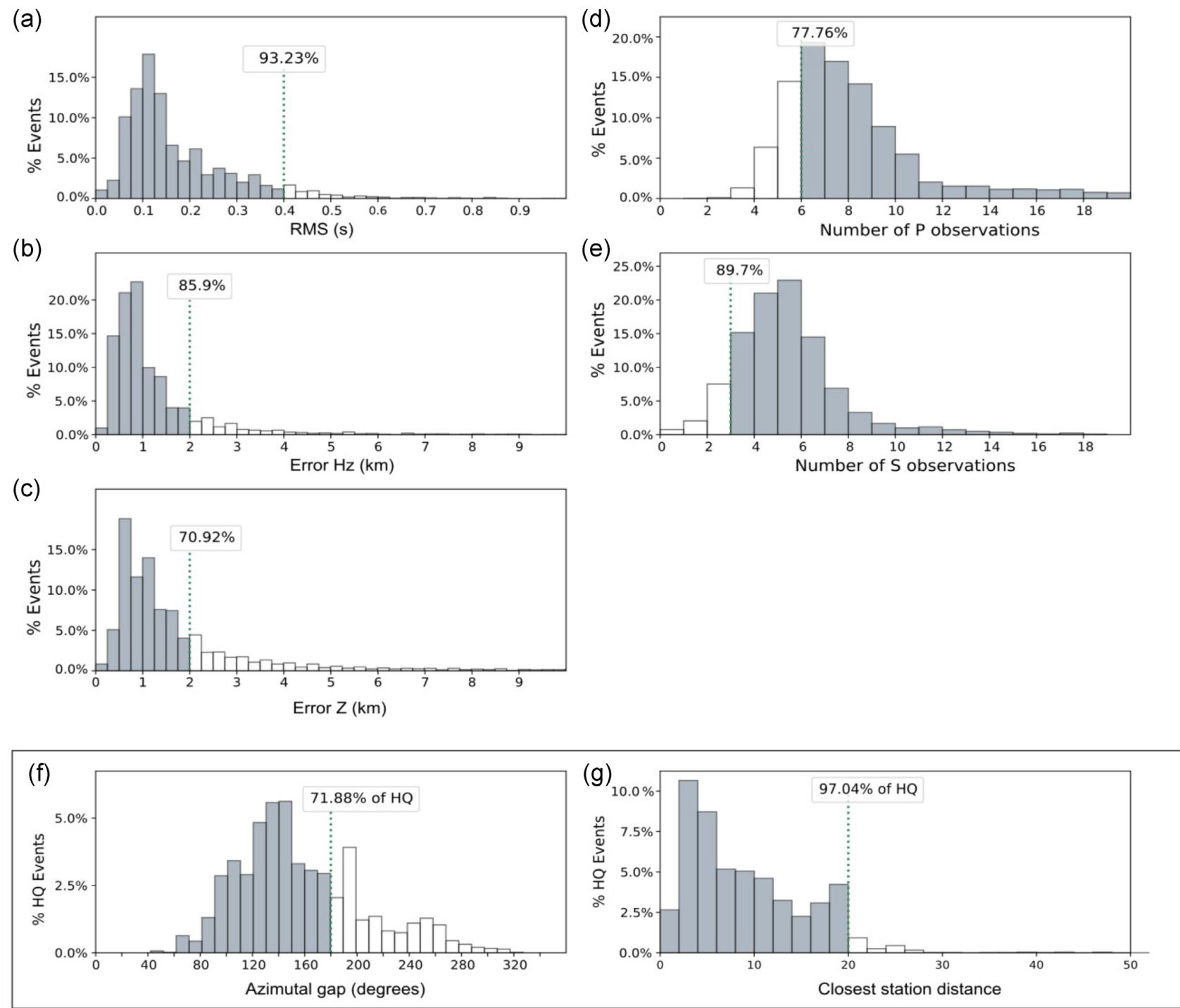

Figure 3. Percentage of events according to different parameters estimated/used from the location procedure. Green dotted lines correspond to quality thresholds fixed from literature (Bondar et al. 2004; Hoste-Colomer et al. 2018) and associated percentage of events validated by the threshold. (a)-(e) Selection criteria for high quality hypocentral locations. On the left, from top to bottom: (a) root mean square error of time residuals (in seconds); (b-c) horizontal and vertical errors associated to earthquake location. On the right, (d-e) the number of $P$ and $S$ observations per event. (f-g) Criteria used for qualifying the precision of high quality events. (f) Azimuthal gap of station observations. (g) Closest station distance from the final epicentral source.

frequency band (above $0.1 \mathrm{~Hz}$ ). The application of this alternative method would also raise additional uncertainties coming from the heterogeneities of the elastic medium and the local topography (Guilhem et al. 2014). We favor the focal plane either dipping toward the Himalayan range or consistent with the geometry of the local seismic cluster associated to the main shock (See Fig. 5 or next section for further discussion).

\section{RESULTS}

The 2 yr of seismicity recorded by HiKNet reveals a seismicity pattern similar at the first order to the pattern revealed by $20 \mathrm{yr}$ of RSC observations (Figs 1 and 5). Indeed, the epicentres are organized in three main seismic belts including several seismic clusters (Figs 1 and 5). The temporary experiment offers the opportunity to determine their hypocentral depths with an improved accuracy. Most events occur at midcrustal depths, 88 per cent of the hypocentres are comprised between 5 and $20 \mathrm{~km}$ below the free topographical surface. This seismicity gently deepens towards north (Fig. 5). We divide the region in two 100-km-long sectors, west and east of AA'. The western sector comprises one wide seismic branch composed of many clusters of pluri-kilometric extent. On the eastern sector, the seismicity splits into two belts composed of a few clusters, parallel to the Himalayan front and separated by a zone of $40 \mathrm{~km}$ devoid of any event (Fig. 5).

Most fault plane solutions indicate reverse faulting (Fig. 5) with $P$-axis generally perpendicular to the Himalayan range.

\subsection{Western sector}

The westernmost and widest belt of Bajhang begins $65 \mathrm{~km}$ north of the Main Frontal Thrust (Fig. 5). Seismicity scatters northward for another $60 \mathrm{~km}$ until disappearing at the edge of the Himalayan front. From the 2627 earthquakes localized in that area, 60 per cent 
(a)

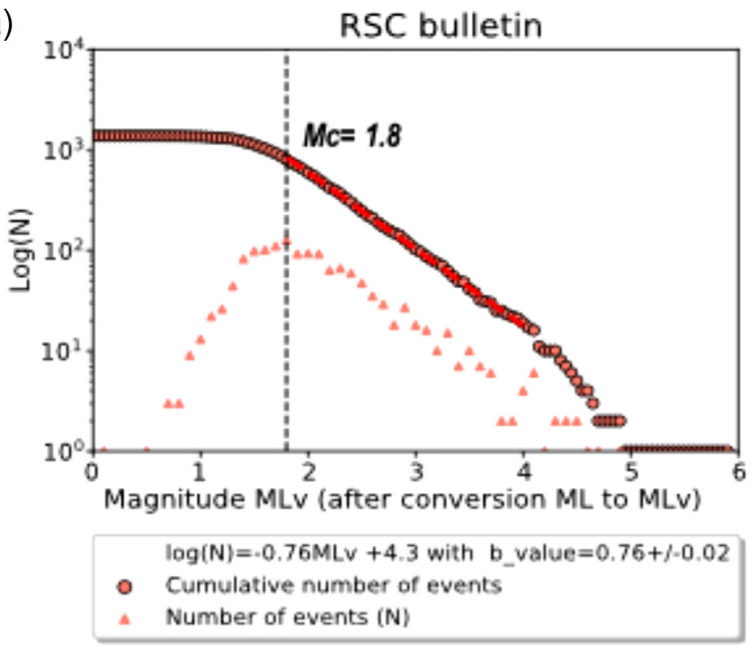

(b)

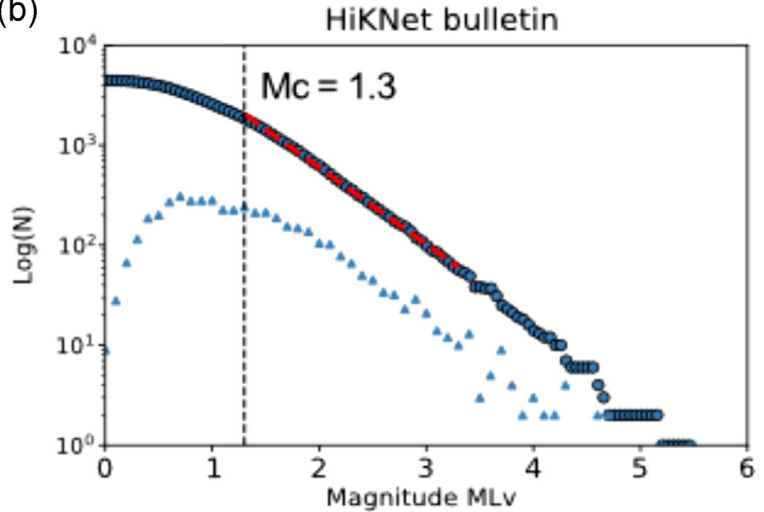

$\log (N)=-0.77 \mathrm{MLv}+4.31$ with b value $=0.77+1-0.016$

Cumulative number of events

4 Number of events (N)

Figure 4. Frequency-magnitude distribution of (a) RSC and (b) HiKNet catalogues. Completeness magnitude of RSC and HiKNet catalogues is estimated at 1.8 and 1.3 , respectively.

Table 1. Fault plane parameters for 11 micro to moderate-size earthquakes. Azimuth, dip and rake of the principal and secondary fault planes are deduced from FPFIT solutions constrained by polarities of the P-wave first arrivals at the exception of the 18/12/15 earthquake which source parameters come from the Global Centroid Moment Tensor (gCMT) Database. See Fig. 5 and Table S2 and Fig. S5.

\begin{tabular}{|c|c|c|c|c|c|c|c|c|c|c|c|c|}
\hline \multirow[b]{2}{*}{ Number } & \multirow[b]{2}{*}{ Date } & \multirow[b]{2}{*}{ Time } & \multirow[b]{2}{*}{ MLv } & \multirow[b]{2}{*}{ Long $\left(^{\circ}\right)$} & \multirow[b]{2}{*}{ Lat $\left(^{\circ}\right)$} & \multirow[b]{2}{*}{ Depth $(\mathrm{km})$} & \multicolumn{3}{|c|}{ Primary fault plane } & \multicolumn{3}{|c|}{ Secondary fault plane } \\
\hline & & & & & & & Azimuth & Dip & Rake & Azimuth & Dip & Rake \\
\hline 1 & $11 / 12 / 14$ & $3: 11$ & 3,7 & 81.0393 & 29.5938 & 13,6 & 260 & 60 & 109 & 45 & 35 & 60 \\
\hline 2 & $28 / 12 / 14$ & $18: 23$ & 3,7 & 81.0535 & 29.5205 & 16,6 & 226 & 38 & 43 & 100 & 65 & 120 \\
\hline 3.A & $5 / 1 / 15$ & $19: 41$ & 4,6 & 81.6727 & 28.968 & 13,9 & 310 & 70 & 0 & 40 & 90 & -160 \\
\hline 3.B & $5 / 1 / 15$ & $19: 41$ & 4,6 & 81.6727 & 28.968 & 13,9 & 325 & 30 & 180 & 180 & 60 & 110 \\
\hline 4 & $22 / 1 / 15$ & $3: 42$ & 4,0 & 81.0298 & 29.3422 & 14,3 & 284 & 31 & 107 & 85 & 60 & 80 \\
\hline 5.A & $22 / 11 / 15$ & $17: 44$ & 3,7 & 81.4565 & 29.2454 & 19,0 & 290 & 20 & 90 & 110 & 70 & 90 \\
\hline 5.B & $22 / 11 / 15$ & $17: 44$ & 3,7 & 81.4565 & 29.2454 & 19,0 & 315 & 50 & 180 & 45 & 90 & 40 \\
\hline 6 & $18 / 12 / 15$ & $22: 16$ & 5,5 & 81.621 & 29.3382 & 17,6 & 314 & 34 & 118 & 102 & 60 & 72 \\
\hline 7 & $4 / 5 / 16$ & $5: 31$ & 3,7 & 81.7847 & 29.3007 & 15,0 & 25 & 15 & 180 & 115 & 90 & 75 \\
\hline 8 & $29 / 6 / 16$ & $9: 10$ & 4,7 & 81.243 & 29.5183 & 18,7 & 299 & 52 & 117 & 80 & 45 & 60 \\
\hline 9 & $29 / 6 / 16$ & $9: 27$ & 4,0 & 81.2423 & 29.5078 & 15,4 & 264 & 32 & 54 & 125 & 65 & 110 \\
\hline 10 & $29 / 6 / 16$ & $9: 33$ & 3,1 & 81.2308 & 29.5308 & 20,1 & 244 & 64 & 66 & 110 & 35 & 130 \\
\hline 11 & $2 / 7 / 16$ & $0: 23$ & 4,2 & 81.2328 & 29.5223 & 18,6 & 277 & 56 & 113 & 60 & 40 & 60 \\
\hline
\end{tabular}

have high quality locations, the magnitude of completeness falls to $0.8\left(M_{\mathrm{Lv}}\right)$ in the centre of this area. A large number of events are localized within seismic clusters. Hereafter, we focus on four of the largest clusters, named W1 to 4 (Fig. 6).

(i) Cluster W1 is a seismic sequence of 197 events beginning on 29 June 2016 with an earthquake of magnitude $M_{\mathrm{Lv}} 4.8$ (Fig. S6). The crisis lasted for $12 \mathrm{~d}$ with two peaks of activity on the first and the fourth day due to an $M_{\mathrm{Lv}} 4.2$ earthquake reviving the crisis on 1 July. The seismicity develops at short distance from $\mathrm{CH} 06$ and BAYN stations (respectively at 5 and 7 km, Fig. 6) depicting no line nor planes but a rather diffuse cluster developing one $8 \mathrm{~km}^{2}$-large area. Hypocentral depths fall between 16 and $21 \mathrm{~km}$. W1 presents a good azimuthal coverage. Eleven high quality events of magnitude $M_{\mathrm{Lv}} \geq 3$ were located allowing us to accurately constrain four focal mechanisms for the main shock and the main aftershocks (F8-F11 in Fig. 6 and Table 1). The focal solutions present a $P$-axis direction perpendicular to the mountain range, with a strike varying between $\mathrm{N} 240^{\circ}$ and $300^{\circ}$ and a dip larger than $35^{\circ}$.

(ii) Cluster W2 consists of a sequence of 287 events with mostly low magnitudes $\left(M_{\mathrm{Lv}} \leq 2\right)$ beginning on 9 December 2014 and lasting for approximately $80 \mathrm{~d}$ (Fig. S7). The event $M_{\mathrm{Lv}} 3.7$ is an exception in terms of magnitudes and occurs $20 \mathrm{~d}$ after the beginning of the crisis on 29 December 2014. For this event, we get the focal mechanism F2 (Fig. 6 and Table 1) and we favor the northward dipping solution which presents an oblique N226 strike. 33 additional events occurred few months later within W2. Events are clustered at an average depth of $15 \mathrm{~km} \pm 1$ along a N110 3-km-long segment at $5 \mathrm{~km}$ from the closest station (ML04).

(iii) A smaller cluster of 47 events (W3) develops $20 \mathrm{~km}$ eastward. It was active during the same period beginning on 8 December 2014 and lasting approximately $80 \mathrm{~d}$ through short bursts of seismicity (Fig. S8). Similarly to W2, W3 includes 10 additional events beginning in November 2015 after a quiescence of a few months.

(iv) W4 corresponds to a major sequence of 430 events following a main shock of magnitude $M_{\mathrm{Lv}} 4.0$ on 22 January 2015 (Fig. S9). The focal mechanism of the main shock (F4 on Fig. 6 and Table 1) displays a northward dipping plane at $31^{\circ}$ which is also the plane the most coherent with the cluster geometry obtained with Hypo71 and HypoDD. 75 per cent of the cluster activity occurred within $8 \mathrm{~d}$ after the main event with two peaks of activity on the first and the 5th day, the second peak resulting from an aftershock of magnitude $M_{\mathrm{Lv}} 3.4$ on 26 January 2015. Earthquakes fall along a 7.5 -km-long $\mathrm{N} 150^{\circ}$ segment at an average depth of $14 \mathrm{~km}$. 


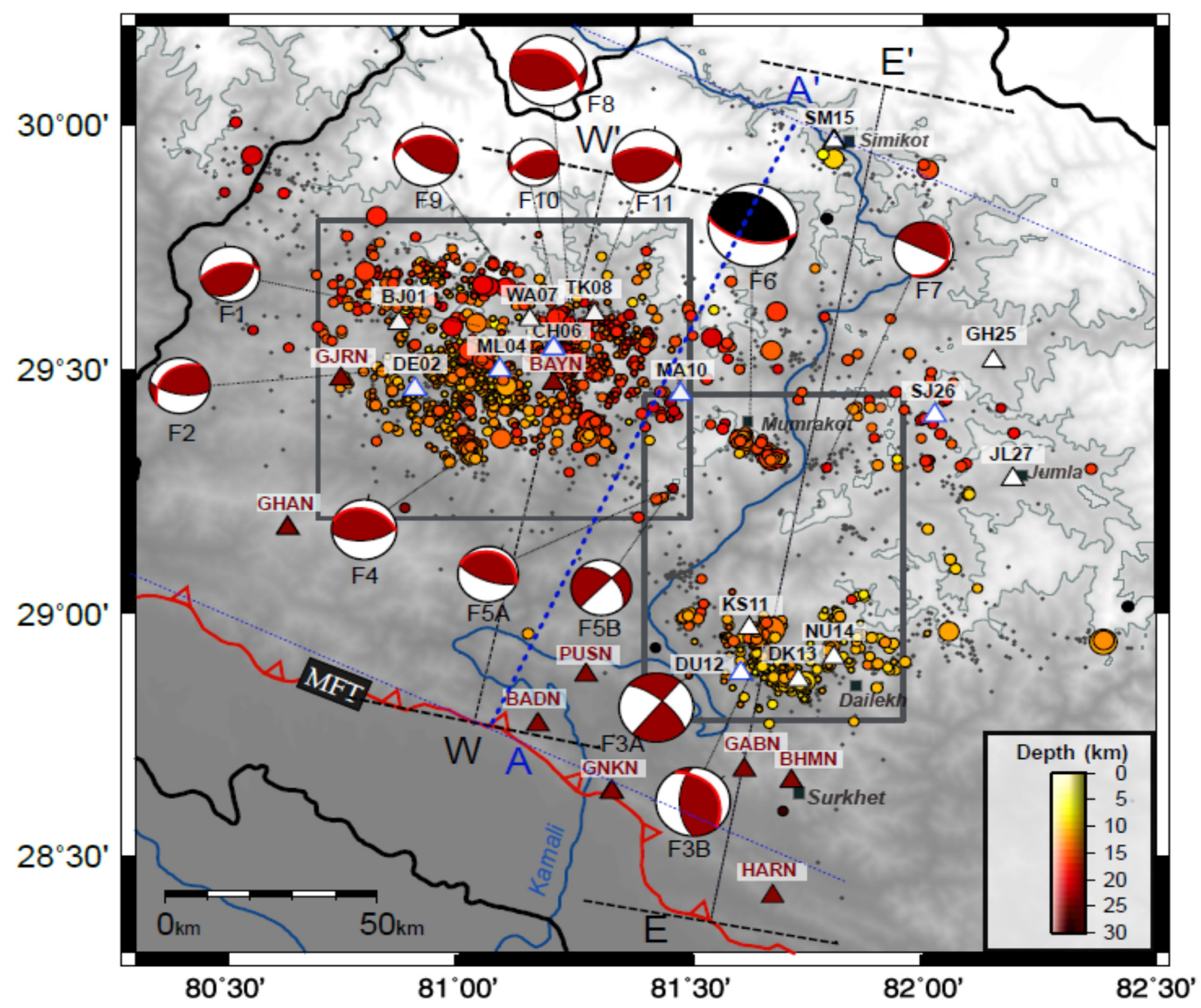

Figure 5. Seismicity recorded by HiKNet experiment between 2014 and 2016. High-quality hypocentral locations (see text) are represented as coloured circles. Size and colour depend respectively on magnitude and focal depth. Background seismicity represented in grey corresponds to the rest of HiKNet data set with fewer constraints on hypocentral locations. RSC permanent stations are red triangles, HiKNet stations are white triangles including LE3D5S with blue contours and CMG40 with black contours. Focal mechanisms estimated from FPFIT are represented in red and the focal mechanism from GCMT catalogue is black. The nodal plane which is most consistent with the tectonic context and/or the cluster geometry is underlined in red. Respective tag numbers refers to the Table 1. White zones embodied by a grey contour emphasize areas of high-topography above the iso-altitude $3500 \mathrm{~m}$.

\subsection{Eastern sector}

At the longitude of the Karnali River $\left(81.5-81.9^{\circ} \mathrm{E}\right)$, the two belts of seismicity are located 60 and $105 \mathrm{~km}$ north of the Main Frontal Thrust (MFT), respectively (Fig. 7).

The northern seismic belt is outlined by the manifestation of one seismic sequence along its southern edge but the RSC long-term catalogue suggests a larger spread of the seismicity from the south border $\left(29.3^{\circ}\right)$ up to the topographic front at $180 \mathrm{~km}$ from the MFT $\left(29.8^{\circ}\right.$, Fig. 1).

(i) Cluster E1 of the northern seismic belt is composed of 204 events (Fig. 7 and S10). Since the closest stations are found at approximately $20 \mathrm{~km}$ west (MA10) and $40 \mathrm{~km}$ east (SJ26), only 21 per cent of earthquakes locations are characterized as highquality. The cluster extends over a 17-km-long and 7-km-large area, oriented on a $\mathrm{N} 115^{\circ}$ straight line similarly to the trend of the southern Karnali seismic belt (Fig. 7). E1 is a seismic sequence beginning on 18 December 2015 after a main shock of $M_{\mathrm{Lv}} 5.5$, the largest event recorded by the network. The Global Centroid Moment tensor
Database (GCMT) reported an almost pure thrust mechanism with a $34^{\circ}$ northward dipping plane oriented $\mathrm{N} 134^{\circ}$ and its conjugate, steeper $60^{\circ}$ southward dipping plane oriented N102 (Table 1 and Fig. S10). The activity lasted for $12 \mathrm{~d}$.

In addition, a small cluster of 22 events aligned develops on $\mathrm{N} 040^{\circ}$ direction at the eastern extension of E1. One focal mechanism (F7 on Fig. 7 and Table 1) is obtained for the 4 May 2016 $M_{\mathrm{Lv}} 3.7$ event (Fig. 7). The focal mechanism shows approximately the same $P$-axis direction as the main shock of December 2015 but its northward dipping solution corresponds to a vertical plane. The $\mathrm{N} 025^{\circ}$ strike of the second focal mechanism is most consistent with the cluster geometry and presents a dip of $15^{\circ}$ which is more realistic than the vertical plane solution (Table 1).

The segment of the southern frontal belt covered by HiKNet is 45 to $50-\mathrm{km}$-long and $10-15-\mathrm{km}$-wide striking approximately $\mathrm{N} 125^{\circ}$. The southern belt $\left(81.58-81.86^{\circ} \mathrm{E} ; 28.76-29.11^{\circ} \mathrm{N}\right)$ is composed of a few clusters activated and reactivated repeatedly through bursts of seismicity. A total of 657 events with an average depth of $11 \mathrm{~km}$ 

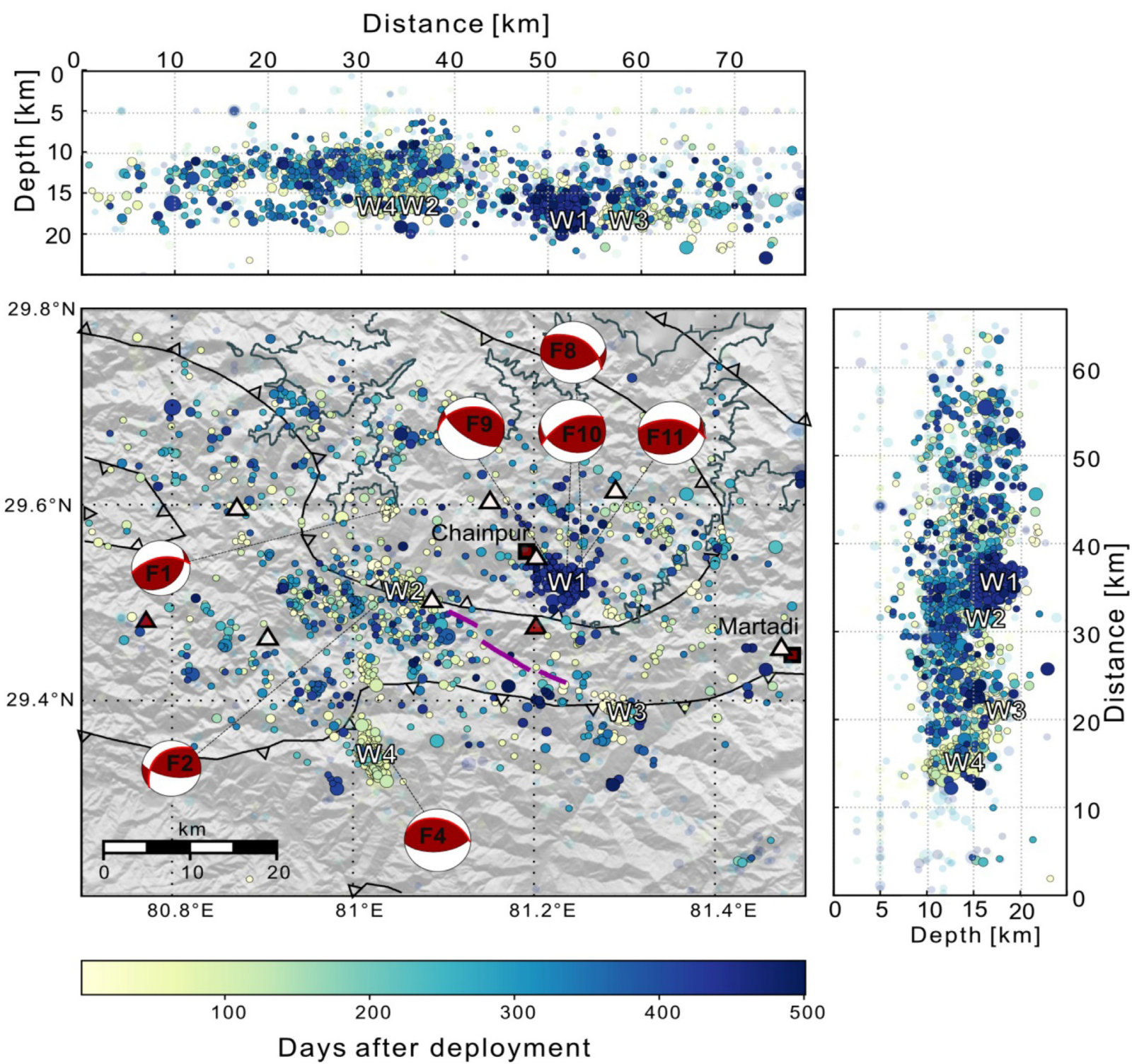

Figure 6. Epicentral distribution of earthquakes and east-west (top panel), north-south (right-hand panel) depth sections within the Bajhang seismic belt colour-coded as a function of time. Low quality locations are made less visible by transparency in the background. Focal mechanisms are red beach balls and the preferred fault plane solution is highlighted in red. Black solid lines represent the geometry of the tectonic features, purple solid lines indicate the active thrust inferred from geomorphological evidences (Nakata 1984). Grey line represents the iso-altitude $3500 \mathrm{~m}$. Stations are represented as triangles, red for permanent stations and white for HiKNet stations.

are recorded in that area. Four temporary stations are sited in the central part of the belt, right above three main clusters E2, E3 and E4.

i) E2, the largest cluster of the southern belt, (Fig. 7) includes 166 events within a $6 \mathrm{~km}$ long and $4.5 \mathrm{~km}$ large area (Fig. S11). Most hypocentres are localized between 12 and $16 \mathrm{~km}$. E2 was activated repeatedly through short bursts of seismicity during the 2 yr but was particularly active during two periods, the first one being initiated on 5 January 2015 by an earthquake of magnitude 4.6 $\left(M_{\mathrm{Lv}}\right)$. This main event was followed by more than 50 earthquakes within the cluster during the next 2 months. One of the two focal mechanisms computed for the main event corresponds to a thrust fault dipping $30^{\circ}$ towards north with a N145 ${ }^{\circ}$ strike coherent with the strike trend of the two seismic belts (F3.B on Fig. 7 and Table 1).
E2 was re-activated three times through bursts of 5-10 events per day followed each-time by a silent period of 1 or 2 months. Its last activity occurred in May 2016 with a burst of 60 earthquakes.

ii) Along the strike trend of the southern seismic belt, to the east, two dense clusters E3 and E4 developed $5 \mathrm{~km}$ apart (Fig. 7). The largest one, E3, includes 168 events smaller than $M_{\mathrm{Lv}} 2.7$ distributed along a 6-km-long segment oriented N045 (Fig. S12). In this area, the temporal behaviour of the seismicity is similar to the temporal behaviour of E2 with repeated occurrences of seismic bursts.

iii) Finally, cluster E4 is composed of 121 events of low magnitudes $\left(M_{\mathrm{Lv}} \leq 3.4\right)$ clustered within a $2.5 \mathrm{~km}^{2}$ area with a peak of seismic activity at the beginning of 2015, lasting from February to March (Fig. S13). E4 focal depths are also tightly constrained between 8.5 and $10 \mathrm{~km}$. 

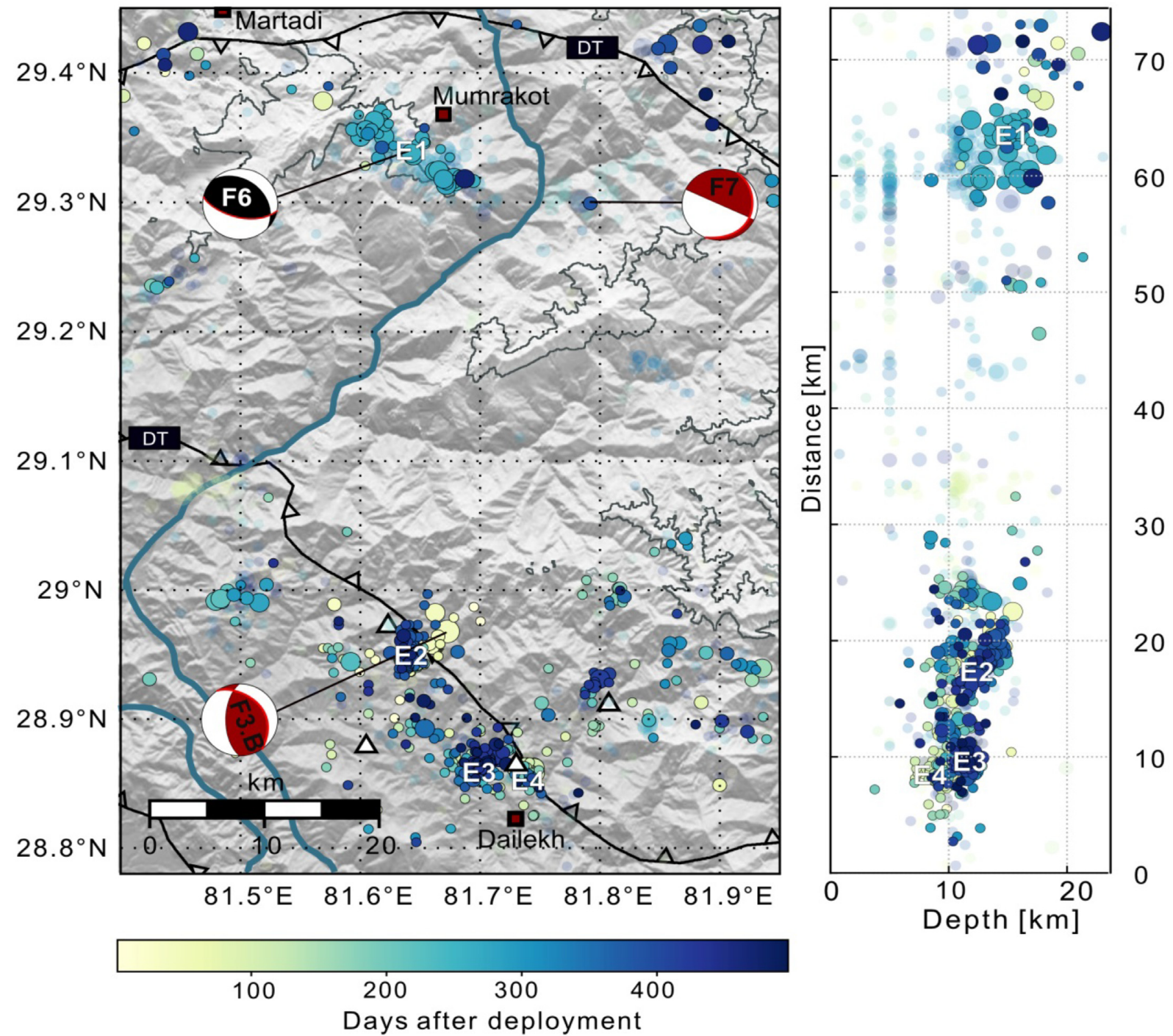

Days after deployment

Figure 7. Epicentral distribution of earthquakes and north-south depth sections within the eastern sector of Karnali, colour-coded as a function of time. Low quality locations are shaded in the background. Karnali river is represented as the blue bold line. gCMT focal mechanism F6 of cluster E1 is indicated as a black beachball. F7 and F3.B mechanisms from this study are represented as red beachballs. Black solid lines represent main tectonic features of the Dadeldhura klippe. Grey line is the line of isoaltitude $3500 \mathrm{~m}$.

\section{DISCUSSION}

These new results can be confronted to the regional geology in order to eventually better understand (1) the general pattern of the seismicity of far western Nepal, (2) the local relation between the seismicity and the geological structures, (3) the mechanisms generating clusters of microseismicity and (4) implications in terms of seismic hazard assessment.

In far western Nepal, the geometry of the MHT at depth is constrained from receiver function imagery (Subedi et al. 2018) and several geological cross-sections (e.g. DeCelles et al. 2001; Robinson et al. 2006; Robinson \& McQuarrie 2012; Olsen et al. 2019).

\subsection{Pattern of the regional seismicity and geophysical imaging}

Recent receiver functions (RF) images highlight the Moho of the India plate, which is northward-dipping $\left(6-12^{\circ} \mathrm{N}\right)$ between 40 and
$60 \mathrm{~km}$ below the area covered by HiKNet (Fig. 8; Subedi et al. 2018). A low velocity zone (LVZ) is observed appreciatively $30 \mathrm{~km}$ above the Moho, between 30-60 km and 60-120 km north of the MFT, in the RF image. In projection on AA' segment, the microseismicity occurs at mid-crustal depths, $30-40 \mathrm{~km}$ above the Moho and is mostly colocated with this LVZ. This LVZ is given to be related with a broad mid-crustal shear zone and thus interpreted as associated with a deep segment of the MHT (Subedi et al. 2018). Below the southern stations (DU12 to NU14 on Fig. 8), the seismicity is slightly shallower but likely falls in the vicinity of the MHT. Given the downdip variations of the MHT, ramps are likely present but these structures are not resolved by the RF images.

\subsection{Local seismicity and geological structures}

The data recovered by the HiKNet experiment corrects epicentral biases of RSC locations (Fig. S1) and refines the clusters locations. 


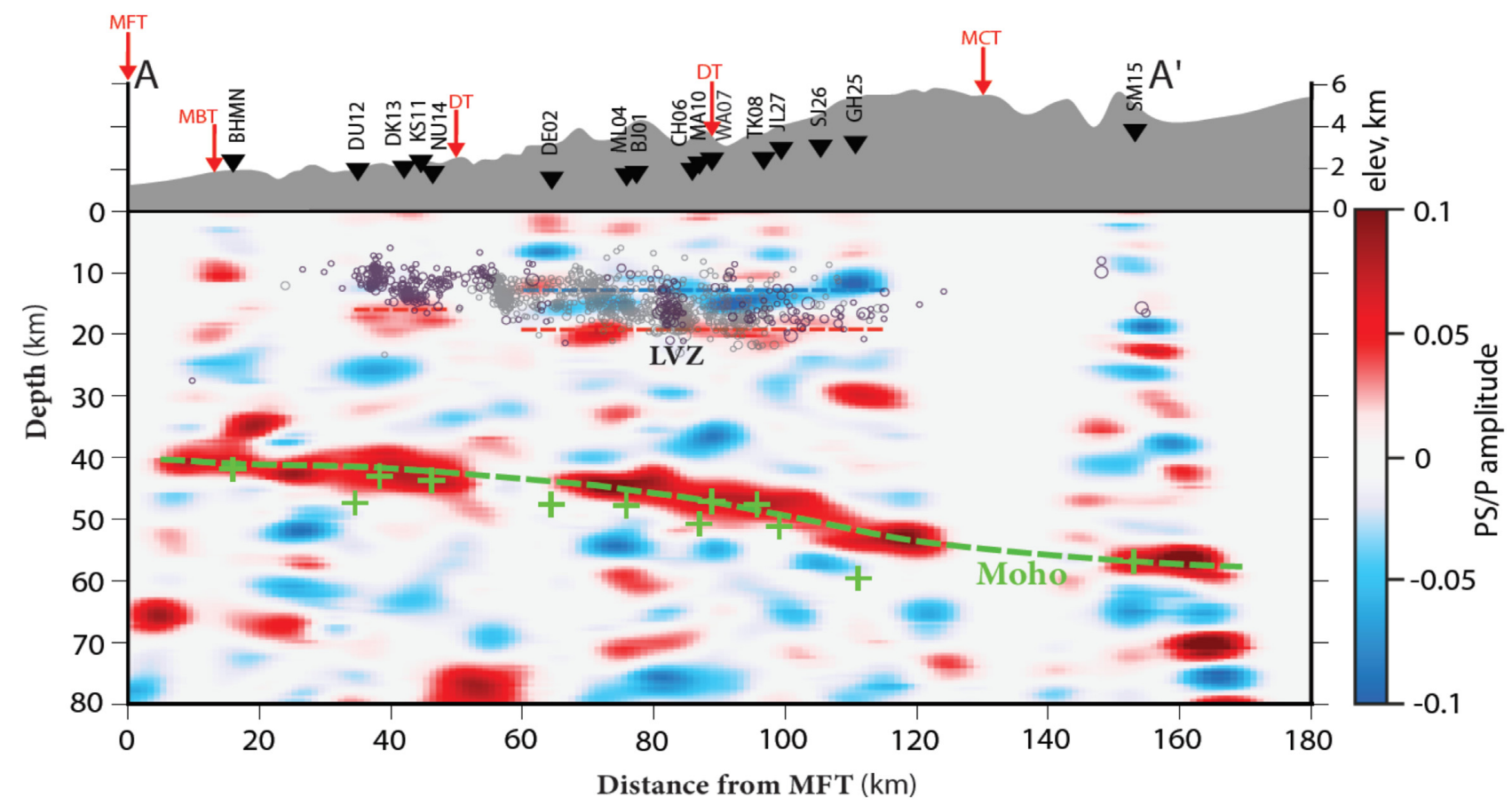

Figure 8. Projection of the 'high quality set' of earthquake hypocentres on the receiver function image (Subedi et al. 2018). The cross-section is constructed from the projection of hypocentral locations of far western Nepal seismicity on the central segment AA' (Fig. 5). Grey and purple earthquakes correspond, respectively, to the western and eastern sides of the section. Green crosses and dashed line for Moho; red and blue dashed lines for bottom and top low velocity zone (LVZ), respectively, from Subedi et al. (2018).

Two distinct seismic patterns were observed in the previous section: (1) on the western side of the network with a $50 \mathrm{~km}$ spread of background seismicity (2) and on the eastern side, below the Karnali network with two distinct seismic belts separated by a $35 \mathrm{~km}$ gap. The correlation in map view between these variations and the surface geology let us suspect a structural control of the seismicity (Fig. 5, see also Hoste-Colomer et al. 2018).

Balanced structural cross-sections can be used to resolve shallow tectonic features. Cross-sections interpretations rely on surface observations but also key subsurface constraints based on geophysical data. The position, dip and depth of the low velocity zone imaged by the receiver function analysis are consistent with the balanced crosssections from Robinson et al. (2006) and Robinson \& McQuarrie (2012). We therefore select these structural models for confrontations with the seismicity and we use the two balanced sections WW' and $\mathrm{EE}$ ', oriented $\mathrm{N} 013^{\circ}$ and $\mathrm{N} 011^{\circ}$ within a $60-\mathrm{km}$-large swath profile, to the west (through Bajhang) and to the east (along Karnali river), respectively. The catalogue of earthquakes is projected on these two cross-sections in order to refine the relation between the seismicity and the flat decollements, the active and passive ramps as well as the lesser Himalayan duplex (Figs 9 and 10).

(i) Western section

First order observations highlight that local earthquakes occur within $10 \mathrm{~km}$ above the MHT lower decollement in the hangingwall, which is constituted of a stack of lesser Himalayan slivers forming the Lesser Himalayan duplex (Fig. 9).

Hypocentral distribution of clusters outlines the main structures of the Himalayan duplex. The large cluster W4 is associated to the $7 \mathrm{~km}$ high, $35^{\circ} \mathrm{N}$ north-dipping mid-crustal ramp (MCR) located $60 \mathrm{~km}$ north of the MFT (Robinson et al. 2006). This frontal cluster roots on the lower decollement, at the base of MCR, and extends vertically for $6 \mathrm{~km}$ following the geologically inferred ramp dip. The focal mechanism F4 associated to the cluster W4, at the base of the ramp, indicates a plane dipping at $31^{\circ} \mathrm{N}\left( \pm 8^{\circ}\right)$, consistent with the $35^{\circ} \mathrm{N}$ dip of the mid-crustal ramp.

To the north, clusters W1-W2 and W3 are also located in the hanging-wall of the MHT within the Lesser Himalayan Duplex, which is principally comprised of Lesser Himalayan tectonic slivers dipping by $35^{\circ}$ towards north (Fig. 9). In map view, W2 and W3 are located along a straight line striking $\mathrm{N} 120^{\circ} \pm 20^{\circ}$ which is parallel to the strike of antiforms and lesser Himalayan slivers in the area (Fig. 5). The projection of hypocentres on the western cross-section supports as well that the seismicity seems to cluster at the vicinity of those tectonic contacts, at the base or along tectonic slivers. One of the two solutions of the focal mechanism F2, associated to the cluster W2, defines a fault plane dipping N038 ${ }^{\circ}$ coinciding with the dip of the sliver but presenting an oblique $P$-axis in regards to the Himalayan front.

Located between two tectonic slivers and below an active thrust documented from aerial photos (Nakata 1984), cluster W1 is characterized by four focal mechanisms. F8 and F9 are both computed from impulsive polarities and associated to lower uncertainties (Fig. S6). However, their north dipping plane respectively dips at $52^{\circ} \pm 10^{\circ}$ and $32^{\circ} \pm 5^{\circ}$, values consistent with the dip of, the active fault (F8) and the dip of the tectonic sliver (F9). Fault plane solutions cannot discriminate between these two structures but do not preclude any of them.

(ii) Eastern section

Based on analysis of localized uplift, structural geology and partial data from the temporary experiment, previous studies have tentatively proposed alternate geometries for the MHT in the eastern profile. In this area, the study extrapolates at first-order the location the two mid-crustal ramps associated with the two seismic branches (RSC network data: Harvey et al. 2015; Olsen et al. 2019; and the incomplete data from the HiKNet experiment: Hoste-Colomer et al. 2018). 

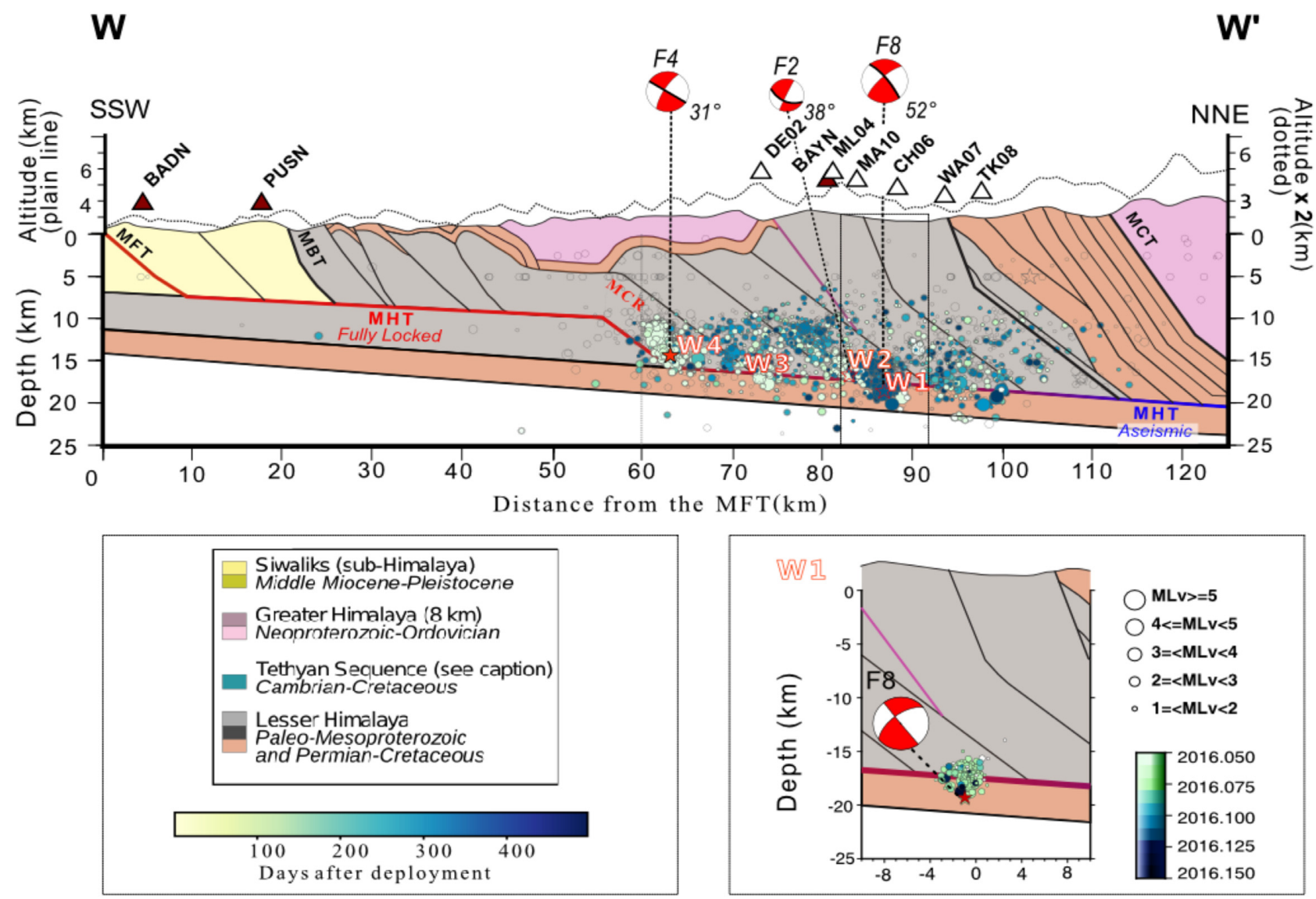

Figure 9. Top panel: projection of hypocentres on Bajhang balanced cross-section (Robinson et al. 2006). Low quality locations are grey empty circles in the background. High quality hypocentres are colour-coded as a function of time. Circle size is proportional to event magnitude. The focal mechanism of the main shock in every cluster is projected on the section. Note that the topography in grey is vertically exaggerated by a factor 2. (Bottom) Zoom on W1 cluster relocated with double difference HypoDD approach (see Fig. S6).

In cross-section, the four clusters (E1-E2-E3-E4) within the two seismic belts are lying at distinct depths. The three clusters of the southern Karnali seismic belt (E2-E3-E4) are shallower than E1 and localized beneath the MHT decollement (Fig. 10) between 9 and $14 \mathrm{~km}$. In South Karnali, epicentres are approximately localized along the same straight line striking $\mathrm{N} 125^{\circ}$ but are spaced out by approximately $5 \mathrm{~km}$ in depth. E2 is the deepest one with a mean depth of $14 \mathrm{~km}$. Two mechanisms F3.A and F3.B are proposed by FPFIT for its largest event and one solution is a reverse fault dipping $22^{\circ}$. Note that two earthquakes located in South Karnali area benefit from multiple solutions computed by FPFIT, one being a thrust and the other a strike-slip mechanism. The two strike-slip solutions are located $50 \mathrm{~km}$ apart and present opposite directions of slip which makes them mechanically inconsistent together. We favor indeed the fault plane solution consistent with a mid-crustal ramp which dips $22^{\circ}$ towards north. Cluster E3 is localized at depth between 10 and $12 \mathrm{~km}$ and cluster E4 at approximately $9 \mathrm{~km}$. Projected on the eastern section the southern seismic belt spreads out for $15 \mathrm{~km}$ from south to north and approximately $5 \mathrm{~km}$ at depth.

The second year of the HiKNet experiment completes the map of regional seismicity in the eastern section by revealing the northern seismic belt associated to the mid-crustal ramp already inferred from geological cross-sections. The cluster E1 is located at the exact location of the mid-crustal ramp McR.N (Robinson et al. 2006; Robinson \& McQuarrie 2012). In the balanced cross sections, the height of this ramp reaches $7 \mathrm{~km}$ which is similar to the depth range of E1 observed in the western section (Fig. 10). E1 is characterized by its focal mechanism F6. One fault plane solution strikes at N134 and dips at $34^{\circ} \mathrm{N}$ which is compatible with the geometry of the ramp derived from the geology. Its conjugate dips at $60 \mathrm{SW}$. The seismicity relocated in the HypoDD catalogue aligns much better along this steeper-southward-dipping fault plane (see Fig. S10). The main shock occurred at the toe of the downdip ramp and was followed by a seismic cluster possibly associated to the activation of a shear zone within the hinge above the flat-decollement/ramp. The activation of the backthrust, which roots in the lower flat-ramp transition, may agree with the mechanical predictions of Souloumiac et al. (2009). This scenario is also consistent with observations at the toe of the ramp North of Kathmandu (Hoste-Colomer et al. 2017).

North of E1, from McR.N to the downdip end of the locked fault zone, microseismicity is unresolved at the scale of the experiment.

The data obtained from the second year of the HiKNet experiment, and particularly the first resolved observation of the two Karnali seismicity belts, advocate for an alternative and refined MHT geometry with two mid-crustal ramps dipping at $35-40^{\circ} \mathrm{E}$ and separated by an aseismic $40-\mathrm{km}$-long, $3^{\circ} \mathrm{E}$ intermediate dipping flat. The balanced geometry of this interpretation implies a lower height of $3.5 \mathrm{~km}$ for both mid-crustal ramps, if we assume that the southern belt of seismicity is located at the base of the lower ramp in the intermediate decollement of the MHT (Fig. 10). The new seismic data set thus enable us to propose a new MHT geometry 

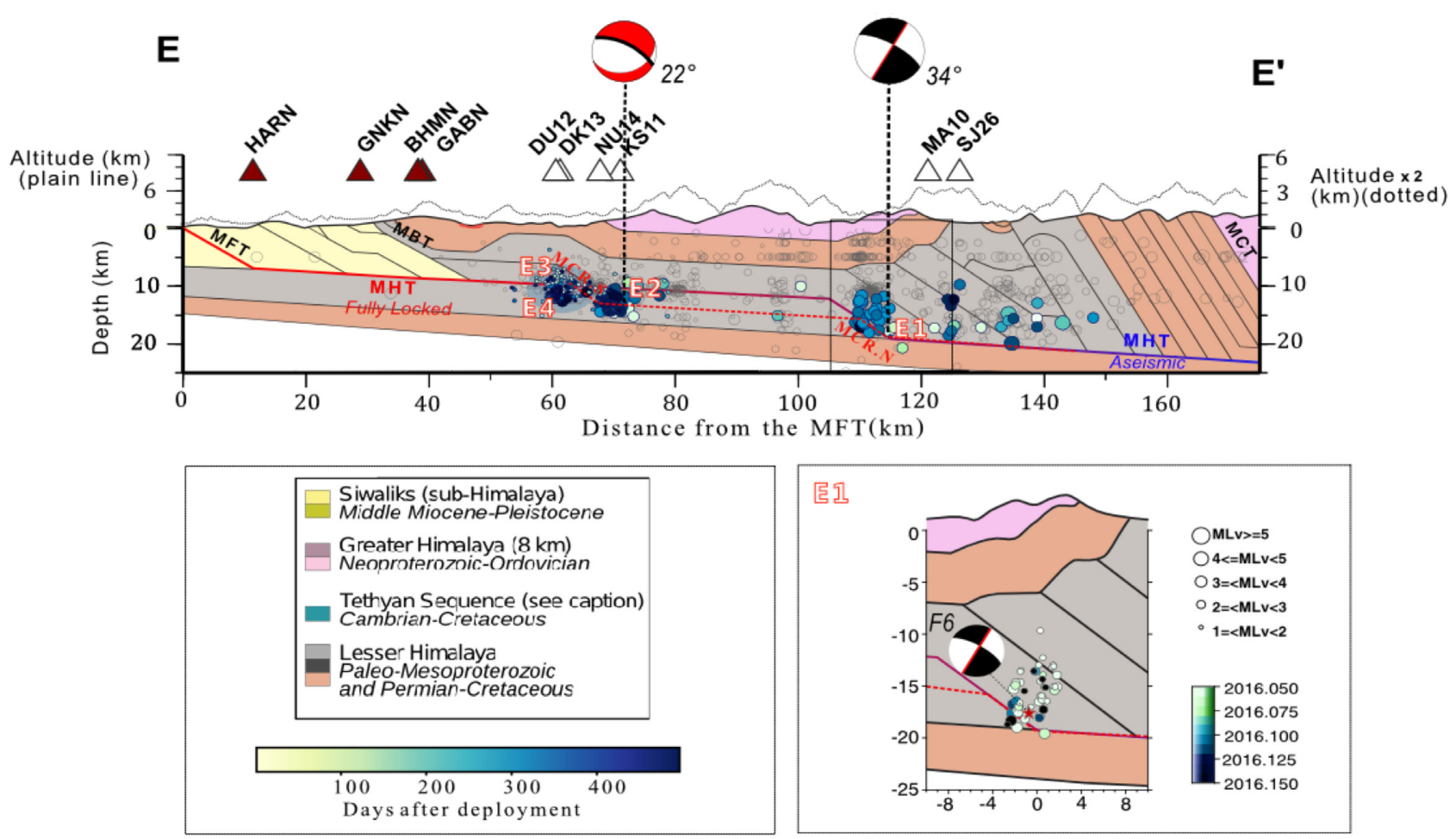

Figure 10. Projection of hypocentres on the balanced cross-section of Karnali (Robinson et al. 2006). Low quality locations are grey empty circles in the background. High quality hypocentres are colour-coded as a function of time. Circle size is proportional to event magnitude. Focal mechanisms F3 and F6 are projected on the section. Note that the topography in grey is vertically exaggerated by a factor 2. Bottom panels: zoom on E1 cluster relocated with double difference HypoDD approach (see Fig. S10).

in agreement with both geophysical (microseismicity and receiver function data: this study, Hoste-Colomer et al. 2018, Subedi et al. 2018) and geological observations (balanced cross sections and topography analysis: Robinson et al. 2006; Robinson \& McQuarrie 2012; Harvey et al. 2015).

\subsection{Processes involved in the generation of microseismicity}

Most of the microseismicity recorded by HiKNet experiment participates to seismic clusters of pluri-kilometric extent along the MHT. Clustering of earthquakes is commonly related to complex interactions between structural heterogeneities and surrounding state of stress. Their most common manifestations are main shockaftershocks sequences characterized by the occurrence of one event of intermediate/large magnitude initiating a seismic crisis with an Omori decay of magnitudes over time. On the other hand, some clusters can be related to seismic swarms, generally described as groups of relatively low-magnitudes events without a clear onset that might arise from short-lived, sometimes recursive, bursts of seismicity (e.g. Duverger et al. 2015; De Barros et al. 2019). Swarms and aftershocks sequences often coexist in megathrusts environments (Boullier et al. 1991; Holtkamp \& Brudzinski 2014) but are associated to distinct evolutions of the seismicity conveying at least two distinct informations on the local processes at play (De Barros et al. 2020). Clusters characterization requires the analysis of their spatio-temporal behaviour discriminating seismic swarms from main shock-aftershocks sequences.

For some clusters, the temporal behaviour of the seismicity is erratic and, locally, likely related to swarm-like sequences. In the southern seismic belt, clusters E2-E3 and E4 are essentially composed of low magnitudes events, in multiple small bursts with no clear onsets (Figs S11, S12 and S13). In the western section, clusters W2 and W3 present similar behaviour at the same time and a slight transient acceleration of the seismicity rate (Figs S7 and S8). Some seismic swarms can be accompanied by seismic migrations, the velocities of which depend on the process involved. Indeed, aseismic slip is sometimes associated to velocity of the order of $\mathrm{km} \mathrm{hr}^{-1}$ whereas fluid migrations generally operate at some dozens of $\mathrm{m} \mathrm{d}^{-1}$ (e.g. DeBarros et al. 2020). Hoste-Colomer et al. (2018) characterized a migration between 35 and $50 \mathrm{~m} \mathrm{~d}^{-1}$ for the cluster W2 consistent with pore-pressure diffusion with a hydraulic diffusivity of approximately $0.3 \mathrm{~m}^{2} \mathrm{~s}^{-1}$ in the media.

The existence of fluids at midcrustal depths along the MHT is mainly attested by the presence of fluids trapped in inclusions preserved in quartz lenses, studied as thermobarometric markers (Craw 1990; Boullier et al. 1991). These fluid inclusions are dominantly composed by $\mathrm{CO}_{2}$ and $\mathrm{H} 2 \mathrm{O}$, trapped in the quartz in the vicinity of the brittle-ductile transition. Fluids circulate also at shallower depths, transported up to the surface along preexisting fault systems, as attested by fluid-gas discharges surveyed along the MCT zone in hot springs (Girault et al. 2014). Some of the microseismicity is associated with fluids circulations at the contact between tectonic slivers above the mid-crustal Low Velocity Zone (Fig. 8) of the MHT. It is therefore highly possible that these fluids are related with the presence of a broad shear zone with high fluid contents.

On the other hand, clusters W1, W4 and E1 are all initiated by one main shock $\left(M_{\mathrm{Lv}} \geq 4\right)$ and followed by a transient sequence of aftershocks with magnitudes decay (Figs S6, S9 and S10). Those clusters describe the most common triggering process of earthquakes: main shock-aftershock sequences. Sequences of aftershocks are usually associated with variations in Coulomb stress or dynamic 
stress changes and are the main processes originating intermediate, large and great earthquakes ruptures. The occurrence of E1 and W4, localized at the base of mid-crustal ramps, thus likely reflect stress building-up there (Bollinger et al. 2004; Singer et al. 2014).

\subsection{Implications for stress build-up and release}

Lateral variations of the seismicity partly reflect the lateral variations of the flats and ramps. These structures are very likely to have a key role in the processes responsible for the seismicity during the interseismic period as well as the coseismic.

\section{Implications deduced from an interseismic cycle perspective}

The structural control on the background seismicity and especially the distribution of small earthquakes clusters during the interseismic period is the main focus of this study. Indeed, the seismicity recorded during the temporary experiment is associated with flats and ramps along the western and eastern cross sections. Our data set illuminates the seismic cluster E1 localized on the midcrustal ramp McR.N which was not spotted during the first year (09/2014-09/2015). Some clusters are associated with swarm-like sequences and probably affected by the presence of deep fluids. However, the coincidence in locations between main clusters and local tectonic structures support the role of the MHT geometry in the distribution of stress build-up and therefore the seismic coupling.

The moment deficit due to interseismic locking has been estimated to increase at a rate of $6.6 \pm 0.4 \times 10^{6} \mathrm{Nm} \mathrm{km}^{-1} \mathrm{yr}^{-1}$ along strike the Nepal Himalayas (Ader et al. 2012) which corresponds to an approximate rate of $1.3 \times 10^{19} \mathrm{Nm} \mathrm{km}^{-1} \mathrm{yr}^{-1}$ when reported to the $200 \mathrm{~km}$ section of far western Nepal. This rate is larger than the rate deduced from most interseismic models that consider local variations of seismic coupling (e.g. Stevens \& Avouac 2015; Jouanne et al. 2017; Lindsey et al. 2018; Dal Zilio et al. 2020). These models are illustrated in Fig. S14 and confronted to the regional seismicity.

Whatever the actual value, this stress build-up is not at all compensated by the stress released by the earthquakes recorded during the experiment. Indeed, the stress released during the $2 \mathrm{yr}$ of experiment reaches $2.0 \times 10^{16} \mathrm{Nm}$ which is about 650 times smaller than the value expected from Ader et al. (2012, Fig. S15). Moreover, 60 per cent of this value of stress release comes from the 10 largest events recorded during the experiment. These values confirm that the background seismicity dissipates only a negligible fraction of the elastic energy associated with the stress build-up. The moderate earthquakes that occur only marginally are also associated with negligible slip on one or two distinct kilometric patches of the fault.

\section{Implications extended to coseismic events}

(i) Intermediate earthquakes $\left(6 \leq M_{\mathrm{w}} \leq 7\right)$

In addition to the micro and moderate earthquakes recorded at RSC network during the last $30 \mathrm{yr}$, the region is also exposed to intermediate earthquakes. Among them, two earthquakes of magnitudes $M_{\mathrm{b}} 6.1$ and $M_{\mathrm{b}} 5.8$ occurred on 29 July 1980 (Molnar \& Lyon-Caen 1989), and an uncommon seismic sequence in 1966 comprising at least two events of $M_{\mathrm{w}} \geq 6$ (ISC Gem earthquake catalogue; Chen \& Molnar 1977; Baranowski et al. 1984). These earthquakes resemble the Chamoli earthquake of magnitude $M_{\mathrm{W}} 6.4$ on 28 March 1999 (Satyabala \& Bilham 2006) and the 19 October 1991 Uttar Kashi earthquake of magnitude $M_{\mathrm{w}} 6.8$ (Cotton et al. 1996), that happened further west in the Garhwal Himalaya. The Chamoli 1999 event ruptured a $13 \times 10 \mathrm{~km}^{2}$ area (Satyabala \& Bilham 2006), attesting that such intermediate earthquakes have the potential to rupture small patches of kilometric extent of the MHT along the brittle-ductile transition zone.

Larger earthquakes occurred also in the region: that was the locus of the 28 August $1916 M_{\mathrm{w}} 7.2$ earthquake (Bilham 2019). Such an event necessarily ruptures a fault patch three to four times than the 1999 Chamoli earthquake, transferring a significant amount of accumulated strain updip without fully unzipping the megathrust. The last earthquake of this type in Nepal is the 2015 Gorkha earthquake of magnitude $M_{\mathrm{w}} 7.9$ which occurred $300 \mathrm{~km}$ east of the studied region (Fig. 1). For this event, evidence of a relation between the structurally segmented locked zone and the seismicity has been proposed (e.g. Grandin et al. 2015, Hoste-Colomer et al. 2017, Baillard et al. 2017; Mendoza et al. 2019; Bai et al. 2019). Hubbard et al. 2016 proposes that the extent of the rupture was limited by a 3-km-high mid-crustal ramp which acted as a geometrical barrier.

In comparison, the 40-km-long middle flat between the two midcrustal ramps of the eastern section has the potential to host the rupture of a large $M_{\mathrm{w}} \geq 7$ earthquake. In that section, the middle flat of the MHT extends for at least $60 \mathrm{~km}$ to the east and is bounded from north to south by two ramps McR.N and McR.S of higher relief and probably of comparable lateral extent than the one that stopped the rupture of Gorkha. In the western section, the lower flat depicted by the geological cross-sections extends as well for $40 \mathrm{~km}$ between the mid-crustal ramp MCR and the brittle/ductile transition zone. Therefore, in far western Nepal, multiple scenarios can lead to the occurrence of a similar event.

(ii) Great earthquakes $\left(M_{\mathrm{w}} \geq 8\right)$

At last, the region is also prone to be affected by a devastating great earthquake, the last of which dates back to more than $500 \mathrm{yr}$ ago. The 1505 earthquake is principally documented by written testimonies and by palaeoseismological investigations attesting that the 1505 event ruptured the MHT from the downdip-end of the locked fault zone up to the surface, covering at least a distance of $120 \mathrm{~km}$ from north to south (Hossler et al. 2016; Yule et al. 2006). However, the lateral extent of the $1505 \mathrm{CE}$ rupture and the return time of similar earthquakes remains poorly documented.

Therefore, the seismicity is multimodal in the region: with ramps and flats that rupture individually during intermediate and large earthquakes and megaquakes $\left(M_{\mathrm{w}} \geq 8\right)$ rupturing multiple fault patches up to the surface. In addition, the regional tectonic setting makes also realistic the re-activation of out of sequence thrusts as well as transverse tectonic structures breaking on the MHT and helping to partition the deformation (e.g. Styron et al. 2011; Fan $\&$ Murphy 2020). This leads to the co-existence of at least two sizes and behaviours of large and great devastating earthquakes as it was proposed by Dal Zilio et al. (2019). This scenario involving the realization of multiple intermediate blind earthquakes, partially rupturing the MHT at depth, in addition to the largest surface rupturing events is consistent with the earthquake-related turbidite record documented in the Rara lake (Fig. 1). Indeed, since $1505 \mathrm{CE}$, at least five seismic events generated strong motions at the lake, triggering turbidics deposits (Ghazoui et al. 2019), a period during which no surface rupturing earthquakes were documented so far. 


\section{CONCLUSIONS: IMPLICATIONS ON GEOMETRY AND SEGMENTATION OF THE MHT}

In this paper, we document the hypocentral location of 4500 earthquakes recorded by the HiKNet, a temporary seismological network deployed during 2 yr (2014-2016) in the trace of 1505 earthquake in far western Nepal. We show that the regional seismicity highlights structures previously inferred from balanced cross-sections. The main seismic clusters we monitor develop along the MHT fault, at the toe of active mid crustal ramps, while some secondary clusters develop within the contact between tectonic slivers, passive thrusts or out-of-sequence active faults in the hanging-wall of the Main Thrust system. Some focal mechanisms help determine the kinematics of the largest earthquakes. The fault plane solutions are consistent within uncertainties with the geometry of the main structures inferred from the seismic clusters. Overall, flats and ramps shaping the MHT geometry primarily control microseismicity. The main clusters reveal along strike heterogeneities: a flat-ramp-flat geometry of the MHT on the western side of the network area and double ramp geometry on the eastern side. Midcrustal ramps approximately 3 -km-high participate to the roughness of the MHT while secondary structures probably accommodate either some internal deformation or localize the percolation of fluids along existing structures. The structural heterogeneities illuminated by the local earthquakes translate therefore the presence of potential barriers and weaknesses along the strike of the MHT, likely controlling the release of the seismogenic potential of the faults, through the fault rupture segmentation. In addition, these structural heterogeneities certainly control some lateral variations in seismic coupling, a hot topic which remains disputed in the region (Jouanne et al. 2017; Lindsey et al. 2018; Dal Zilio et al. 2020) and will require denser geodetic measures.

\section{ACKNOWLEDGEMENTS}

The HiKNet experiment and project BHUTANEPAL were supported by the French national research agency (Grant ANR13BS06-006-01). The instruments temporary deployed in Nepal belong to the French national pool of portable seismic instruments SISMOB-RESIF (CNRS-INSU). The Department of Mines and Geology of Nepal, Nepalese National Earthquake Monitoring and Research Center (NEMRC), is thanked for its implication in the deployment of the HiKNet network and the access to permanent Nepalese seismic stations. We acknowledge the Yves Rocard Joint Laboratory (ENS, CNRS and CEA/DASE) for hosting this work. We thank Claudio Satriano for early-access to SourceSpec algorithm, Luca Dal Zilio and François Jouanne for sharing their seismic coupling grids and Aurélie Guilhem Trilla for her expertise on the limitations of the regional inversion method for focal mechanisms. Finally, the authors also thank the editor, Prof Huajian Yao and Shenji Wei and an anonymous reviewer for their helpful comments that improved the paper.

\section{DATA AVAILABILITY STATEMENT}

The seismic signals from the HiKNet temporary experiment are publicly available and distributed under CC-BY 4.0 License following the French national research agency rules in the framework of RESIF-EPOS, a Research Infrastructure (RI) managed by CNRS-INSU. http://dx.doi.org/10.157778/RESIF.ZO2014. The source code of SourceSpec algorithm is available under the
DOI: 10.5281/ZENODO.3 688587 (Satriano 2020). Hypo71 and HypoDD catalogues are available in the online supplementary data material (Tables S3 and S4).

\section{REFERENCES}

Acton, C.E., Priestley, K. \& Mitra, S., 2011. Crustal structure of the Darjeeling-Sikkim Himalaya and southern Tibet, Geophys. J. Int., 184(2), 829-852.

Ader, T., Avouac, J.P. \& Liu-Zeng, J., 2012. Convergence rate across the Nepal Himalaya and interseismic coupling on the Main Himalayan Thrust: implications for seismic hazard, J. geophys. Res., 117(B4), doi:10.1029/2011JB009071.

Adhikari, L.B., Gautam, U.P. \& Koirala, B., 2015. The aftershock sequence of the April 252015 Gorkha-Nepal earthquake, Geophys. J. Int., 203, 2119-2124.

Akaike, H., 2011. Akaike's information criterion, in International Encyclopedia of Statistical Science, ed. Lovric, M., Springer.

Avouac, J.P., 2015. From geodetic imaging of seismic and aseismic fault slip to dynamic modeling of the seismic cycle, Annu. Rev. Earth planet. Sci..,43, 233-271.

Bai, L., Klemperer, S.L. \& Mori, J., 2019. Lateral variation of the Main Himalayan Thrust controls the rupture length of the 2015 Gorkha earthquake in Nepal, Sci. Adv., 5(6), eaav0723, doi:10.1126/sciadv.aav0723.

Baillard, C., Lyon-Caen, H. \& Bollinger, L., 2017. Automatic analysis of the Gorkha earthquake aftershock sequence: evidences of structurally segmented seismicity, Geophys. J. Int., 209(2), 1111-1125.

Baranowski, J., Armbruster, J. \& Seeber., L., 1984. Focal depths and fault plane solutions of earthquakes and active tectonics of the Himalaya, $J$. geophys. Res., 89(B8), 6918-6928.

Benoit, A., 2016. Apport de la micro-sismicité à l'étude des grands chevauchements himalayens, MSc thesis, pp. 1-30, University Montpellier, CEA, France.

Bettinelli, P., Avouac, J.P. \& Flouzat, M., 2006. Plate motion of India and interseismic strain in the Nepal Himalaya from GPS and DORIS measurements, J. Geod., 80(8-11), 567-589.

Bilham, R., Gaur, V.K. \& Molnar, P., 2001. Himalayan seismic hazard, Science, 293(5534), 1442-1444.

Bilham, R., 2019. Himalayan earthquakes: a review of historical seismicity and early 21 st century slip potential, Geol. Soc., Lond., Spec. Publ., 483(1), 423-482.

Bollinger, L., Avouac, J.P. \& Cattin, R., 2004. Stress buildup in the Himalaya, J. geophys. Res., 109(B11), doi:10.1029/2003JB002911.

Bollinger, L., Sapkota, S.N. \& Tapponnier, P., 2014. Estimating the return times of great Himalayan earthquakes in eastern Nepal: evidence from the Patu and Bardibas strands of the Main Frontal Thrust, J. geophys. Res., 119(9), 7123-7163.

Bondár, I., Myers, S.C. \& Engdahl, E.R., 2004. Epicentre accuracy based on seismic network criteria, Geophys. J. Int., 156(3), 483-496.

Boullier, A.M., France-Lanord, C. \& Dubessy, J., 1991. Linked fluid and tectonic evolution in the High Himalaya mountains (Nepal), Contrib. Mineral. Petrol., 107(3), 358-372.

Buland, R., 1976. The mechanics of locating earthquakes, Bull. seism. Soc. Am., 66(1), 173-187.

Bürgmann, R., Kogan, M.G. \& Steblov, G.M., 2005. Interseismic coupling and asperity distribution along the Kamchatka subduction zone, J. geophys. Res., 110, B07405, doi:10.1029/2005JB003648

Burtin, A., Bollinger, L. \& Vergne, J., 2007. Spatial and continuous observations of stream hydrodynamics and bedload transport from spectral analysis of river induced seismic noise, in $A G U$ Fall Meeting Abstracts H51E-0793.

Burtin, A., Bollinger, L. \& Cattin, R., 2009. Spatiotemporal sequence of Himalayan debris flow from analysis of high-frequency seismic noise, $J$. geophys. Res., 114(F4), doi:10.1029/2008JF001198.

Cattin, R. \& Avouac, J.P., 2000. Modeling mountain building and the seismic cycle in the Himalaya of Nepal, J. geophys. Res., 105(B6), 13 389-13 407. 
Chen, W.P. \& Molnar, P., 1977. Seismic moments of major earthquakes and the average rate of slip in central Asia. J. geophys. Res., 82(20), 2945-2969.

Cotton, F., Campillo, M. \& Deschamps, A., 1996. Rupture history and seismotectonics of the 1991 Uttarkashi, Himalaya earthquake, Tectonophysics, 258, 35-51.

Craw, D., 1990. Fluid evolution during uplift of the Annapurna Himal, central Nepal, Lithos, 24(2), 137-150.

Dal Zilio, L., Van Dinther, Y. \& Gerya, T., 2019. Bimodal seismicity in the Himalaya controlled by fault friction and geometry, Nat. Commun., 10(1), 1-11.

Dal Zilio, L., Jolivet, R. \& Van Dinther, Y., 2020. Segmentation of the Main Himalayan Thrust illuminated by Bayesian inference of interseismic coupling, Geophys. Res. Lett., 47(4), e2019GL086424, doi:10.1029/2019GL086424.

De Barros, L., Baques, M. \& Godano, M., 2019. Fluid-induced swarms and coseismic stress transfer: a dual process highlighted in the aftershock sequence of the 7 April 2014 earthquake (Ml 4.8, Ubaye, France), J. geophys. Res., 124, 3918-3932.

De Barros, L., Cappa, F. \& Deschamps, A., 2020. Imbricated aseismic slip and fluid diffusion drive a seismic swarm in the Corinth Gulf, Greece, Geophys. Res. Lett., 47(9), e2020GL087142, doi:10.1029/2020GL087142.

DeCelles, P.G., Robinson, D.M. \& Quade, J., 2001. Stratigraphy, structure, and tectonic evolution of the Himalayan fold-thrust belt in western Nepal, Tectonics, 20(4), 487-509.

Diehl, T., Singer, J. \& Hetényi, G., 2017. Seismotectonics of Bhutan: evidence for segmentation of the Eastern Himalayas and link to foreland deformation, Earth planet. Sci. Lett., 471, 54-64.

Duverger, C., Godano, M. \& Bernard, P., 2015. The 2003-2004 seismic swarm in the western Corinth rift: evidence for a multiscale pore pressure diffusion process along a permeable fault system, Geophys. Res. Lett., 42(18), 7374-7382.

Dziewonski, A.M., Chou, T.-A. \& Woodhouse, J.H., 1981. Determination of earthquake source parameters from waveform data for studies of global and regional seismicity, J. geophys. Res., 86, 2825-2852.

Ekström, G., Nettles, M. \& Dziewonski, A.M., 2012. The global CMT project 2004-2010: centroid-moment tensors for 13,017 earthquakes, Phys. Earth planet. Inter., 200-201, 1-9.

Fan, S. \& Murphy, M.A., 2020. Three-dimensional strain accumulation and partitioning in an arcuate orogenic wedge: an example from the Himalaya, Bull. geol. Soc. Am., 133, 3-18.

Ghazoui, Z., Bertrand, S. \& Vanneste, K., 2019. Potentially large post-1505 $\mathrm{AD}$ earthquakes in western Nepal revealed by a lake sediment record, Nature communications, 10(1), 1-9.

Girault, F., Bollinger, L. \& Battarai, M., 2014. Large-scale organization of carbon dioxide discharge in the Nepal Himalayas, Geophys. Res. Lett., 41(18), 6358-6366.

Goertz-Allmann, B.P., Edwards, B. \& Bethmann, F., 2011. A new empirical magnitude scaling relation for Switzerland, Bull. seism. Soc. Am., 101(6), 3088-3095.

Grandin, R., Vallée, M. \& Satriano, C., 2015. Rupture process of the Mw = 7.92015 Gorkha earthquake (Nepal): insights into Himalayan megathrust segmentation, Geophys. Res. Lett., 42(20), 8373-8382.

Guilhem, A., Hutchings, L. \& Dreger, D.S., 2014. Moment tensor inversions of $\mathrm{M} \sim 3$ earthquakes in the Geysers geothermal fields, California, $J$. geophys. Res., 119(3), 2121-2137.

Harvey, J.E., Burbank, D.W. \& Bookhagen, B., 2015. Along-strike changes in Himalayan thrust geometry: topographic and tectonic discontinuities in western Nepal, Lithosphere, 7(5), 511-518.

Herman, M.W., Furlong, K.P. \& Govers, R., 2018. The accumulation of slip deficit in subduction zones in the absence of mechanical coupling: implications for the behavior of megathrust earthquakes, J. geophys. Res., 123(9), 8260-8278

Holtkamp, S. \& Brudzinski, M.R., 2014. Megathrust earthquake swarms indicate frictional changes which delimit large earthquake ruptures, Earth planet. Sci. Lett., 390, 234-243.

Hossler, T., Bollinger, L. \& Sapkota, S.N., 2016. Surface ruptures of large Himalayan earthquakes in western Nepal: evidence along a reactivated strand of the Main Boundary Thrust, Earth planet. Sci. Lett., 434, 187196.

Hoste-Colomer, R., Bollinger, L. \& Lyon-Caen, H., 2017. Lateral structure variations and transient swarm revealed by seismicity along the Main Himalayan Thrust north of Kathmandu, Tectonophysics, 714, 107-116.

Hoste-Colomer, R., Bollinger, L. \& Lyon-Caen, H., 2018. Lateral variations of the midcrustal seismicity in western Nepal: seismotectonic implications, Earth planet. Sci. Lett., 504, 115-125.

Hubbard, J., Almeida, R. \& Foster, A., 2016. Structural segmentation controlled the $2015 \mathrm{Mw} 7.8$ Gorkha earthquake rupture in Nepal, Geology, 44(8), 639-642.

Jouanne, F., Mugnier, J.L., Sapkota, S.N., Bascou, P. \& Pecher, A., 2017. Estimation of coupling along the Main Himalayan Thrust in the central Himalaya, J. Asian Earth Sci., 133, 62-71.

Karplus, M., Pant, M. \& Sapkota, S.N., 2020. A rapid response network to record aftershocks of the 2015 M 7.8 Gorkha earthquake in Nepal, Seismol. Res. Lett., 91(4), 2399-2408.

Kissling, E., Kradolfer, U. \& Maurer, H., 1995. Program VELEST User'S Guide-Short Introduction. Institute of Geophysics, ETH Zurich.

Kurashimo, E., Sato, H. \& Sakai, S.I., 2019. The 2015 Gorkha earthquake: earthquake reflection imaging of the source fault and connecting seismic structure with fault slip behavior, Geophys. Res. Lett., 46(6), 3206-3215.

Lavé, J. \& Avouac, J.P., 2000. Active folding of fluvial terraces across the Siwaliks Hills, Himalayas of central Nepal, J. geophys. Res., 105(B3), $5735-5770$

Lee, W.H.K. \& Lahr, J.C., 1972. HYPO71: a computer program for determining hypocenter, magnitude, and first motion pattern of local earthquakes, Open-File Report, US Department of the Interior, Geological Survey, 100 leaves, doi:10.3133/ofr72224.

Lindsey, E.O., Almeida, R. \& Mallick, R., 2018. Structural control on downdip locking extent of the Himalayan megathrust, J. geophys. Res., 123(6), 5265-5278.

Mendoza, M.M., Ghosh, A. \& Karplus, M.S., 2019. Duplex in the Main Himalayan Thrust illuminated by aftershocks of the $2015 \mathrm{M} \mathrm{w} 7.8$ Gorkha earthquake, Nat. Geosci., 1-5.

Métois, M., Vigny, C. \& Socquet, A., 2016. Interseismic coupling, megathrust earthquakes and seismic swarms along the Chilean subduction zone, Pure appl. Geophys., 173(5), 1431-1449.

Molnar, P. \& Lyon-Caen, H., 1989. Fault plane solutions of earthquakes and active tectonics of the Tibetan Plateau and its margins, Geophys. J. Int., 99(1), 123-153.

Monsalve, G., Sheehan, A. \& Schulte-Pelkum, V., 2006. Seismicity and one-dimensional velocity structure of the Himalayan collision zone: earthquakes in the crust and upper mantle, J. geophys. Res., 111(B10), doi:10.1029/2005JB004062.

Nabelek, J., Hetenyi, G. \& Vergne, J., 2009. Underplating in the HimalayaTibet Collision Zone revealed by the Hi-CLIMB experiment, Science, 325(5946), 1371-1374

Nakata, T., 1984. Tectonic landforms of several active faults in the western Nepal Himalayas, J. Nepal Geol. Soc., 4, 177-200.

Olsen, J.E., McQuarrie, N. \& Robinson, D.M., 2019. Determining kinematic order and relative age of faulting via flexural-kinematic restoration: a case study in far western Nepal, Basin Res., 31(6), 1153-1177.

Pandey, M.R., 1985. Seismic model of central and eastern lesser Himalaya of Nepal, J. Geol. Soc. Nepal., 3, 1-11.

Pandey, M.R., Tandukar, R.P., Avouac, J.P., Lave, J. \& Massot, J.P., 1995. Interseismic strain accumulation on the Himalayan crustal ramp (Nepal), Geophys. Res. Lett., 22(7), 751-754.

Qiu, Q., Hill, E.M. \& Barbot, S., 2016. The mechanism of partial rupture of a locked megathrust: the role of fault morphology, Geology, 44(10), 875-878.

Reasenberg, P.A., 1985. FPFIT, FPPLOT, and FPPAGE: fortran computer programs for calculating and displaying earthquake fault-plane solutions, US Geol. Surv. Open-File Rep. 85-739.

Richter, C.F., 1935. An instrumental earthquake magnitude scale, Bull. seism. Soc. Am.., 25(1), 1-32 
Robinson, D.M., DeCelles, P.G. \& Copeland, P., 2006. Tectonic evolution of the Himalayan thrust belt in western Nepal: implications for channel flow models, Bull. geol. Soc. Am., 118(7-8), 865-885.

Robinson, D.M. \& McQuarrie, N., 2012. Pulsed deformation and variable slip rates within the central Himalayan thrust belt, Lithosphere, 4(5), 449-464.

Ross, Z.E., Cochran, E.S., Trugman, D.T. \& Smith, J.D., 2020. 3D fault architecture controls the dynamism of earthquake swarms, Science, 368(6497), $1357-1361$.

Satriano, C., 2020. SourceSpec - Earthquake source parameters from Swave displacement spectra. doi:10.5281/ZENODO.3688587.

Satyabala, S.P. \& Bilham, R., 2006. Surface deformation and subsurface slip of the 28 March $1999 \mathrm{Mw}=6.4$ west Himalayan Chamoli earthquake from InSAR analysis, Geophys. Res. Lett.., 33(23), doi:10.1029/2006GL027422.

Schelling, D. \& Arita, K., 1991. Thrust tectonics, crustal shortening, and the structure of the far-eastern Nepal Himalaya, Tectonics, 10(5), 851-862.

Schulte-Pelkum, V., Monsalve, G. \& Sheehan, A., 2005. Imaging the Indian subcontinent beneath the Himalaya, Nature, 435(7046), 1222-1225.

Singer, J., Hetényi, G. \& Diehl, T., 2014. Structure of the orogenic wedge in the Bhutan Himalaya: first results from the GANSSER seismic experiment, T21B-4573, in Proceedings of the American Geophysical Union $A G U$, San Francisco, USA.

Sippl, C., Schurr, B. \& Asch, G., 2018. Seismicity structure of the northern Chile forearc from $>100,000$ double-difference relocated hypocenters, $J$. geophys. Res., 123(5), 4063-4087.

Souloumiac, P., Leroy, Y.M. \& Maillot, B., 2009. Predicting stress distributions in fold-and-thrust belts and accretionary wedges by optimization, $J$. geophys. Res., 114(B9), doi:10.1029/2008JB005986.

Stevens, V.L. \& Avouac, J.P., 2015. Interseismic coupling on the main Himalayan thrust, Geophys. Res. Lett., 42(14), 5828-5837.

Styron, R.H., Taylor, M.H. \& Murphy, M.A., 2011. Oblique convergence, arc-parallel extension, and the role of strike-slip faulting in the High Himalaya, Geosphere, 7(2), 582-596.

Subedi, S., Hetényi, G. \& Vergne, J., 2018. Imaging the Moho and the Main Himalayan Thrust in Western Nepal with receiver functions, Geophys. Res. Lett., 45, 13 222-13 230.

Tichelaar, B.W. \& Ruff, L.J., 1993. Depth of seismic coupling along subduction zones, J. geophys. Res., 98(B2), 2017-2037.

Waldhauser, F. \& Ellsworth, W.L., 2000. A double-difference earthquake location algorithm: method and application to the northern Hayward fault, California, Bull. seism. Soc. Am., 90(6), 1353-1368.

Wang, X., Wei, S. \& Wu, W., 2017. Double-ramp on the Main Himalayan Thrust revealed by broadband waveform modeling of the 2015 Gorkha earthquake sequence. Earth planet. Sci. Lett., 473, 83-93.

Weber, B., Becker, J. \& Hanka, W., 2007. SeisComP3-Automatic and interactive real time data processing, Geophys. Res. Abstr., 9(09), 219.

Yamada, M., Kandel, T. \& Tamaribuchi, K., 2020. 3D fault structure inferred from a refined aftershock catalog for the 2015 Gorkha earthquake in Nepal, Bull. seism. Soc. Am., 110(1), 26-37.

Yule, D., Dawson, S. \& Lave, J., 2006. Possible evidence for surface rupture of the Main Frontal Thrust during the great 1505 Himalayan earthquake, far-western Nepal, Am. Geophys. Union Fall Meeting, Abstracts \#S33C05.

\section{SUPPORTING INFORMATION}

Supplementary data are available at $G J I$ online.

Figure S1. (a) Rose diagram representing the azimuthal offset between RSC and HiKNet common events in far western Nepal; (b) epicentral offset between RSC and HiKNet common events in far western Nepal; (c) epicentral offset between RSC and HiKNet common events in the western sector; (d) rose diagram representing the azimuthal offset between RSC and HiKNet common events in the western sector; (e) epicentral offset between RSC and HiKNet common events in the south eastern sector and (f) rose diagram representing the azimuthal offset between RSC and HiKNet common events in the south eastern sector.

Figure S2. Least squares regression relating HiKNet bulletin magnitude MLv to RSC local magnitude ML. Top and side plots are histograms displaying the number of events as a function of magnitude.

Figure S3. Differences estimated between RSC local magnitude and magnitudes from HiKNet bulletin (grey dots) and ISC bulletins (coloured dots).

Figure S4. Difference between Mw and MLv as a function of MLv compared to the three step regression proposed for Switzerland (Goertz-Allmann et al. 2011).

Figure S5. Comparison of FPFIT focal solutions (black and white beach balls) and manual focal solutions (grey and green beachballs) for the 10 selected events computed in this study.

Figure S6. Description of the spatio-temporal behaviour of cluster W1. (a) Close map view of Hypo 71 locations; (b) close map view of HypoDD locations; (c) projection of Hypo 71 locations on a N30 segment; (d) projection of HypoDD locations on a N30 segment and (e) distribution of magnitudes as a function of time. Plain red line is the cumulative number of events.

Figure S7. Description of the spatio-temporal behaviour of cluster W2. (a) Close map view of Hypo 71 locations; (b) close map view of HypoDD locations; (c) projection of Hypo 71 locations on a N30 segment; (d) projection of HypoDD locations on a N30 segment and (e) distribution of magnitudes as a function of time. Plain red line is the cumulative number of events.

Figure S8. Description of the spatio-temporal behaviour of cluster W3. (a) Close map view of Hypo71 locations; (b) close map view of HypoDD locations; (c) projection of Hypo 71 locations on a $\mathrm{N} 30^{\circ}$ segment; (d) projection of HypoDD locations on a N30 segment and (e) distribution of magnitudes as a function of time. Plain red line is the cumulative number of events.

Figure S9. Description of the spatio-temporal behaviour of cluster W4. (a) Close map view of Hypo71 locations; (b) close map view of HypoDD locations; (c) projection of Hypo 71 locations on a N30 segment; (d) projection of HypoDD locations on a N30 segment and (e) distribution of magnitudes as a function of time. Plain red line is the cumulative number of events.

Figure S10. Description of the spatio-temporal behaviour of cluster E1. (a) Close map view of Hypo71 locations; (b) close map view of HypoDD locations; (c) projection of Hypo 71 locations on a N30 segment; (d) projection of HypoDD locations on a N30 segment and (e) distribution of magnitudes as a function of time. Plain red line is the cumulative number of events.

Figure S11. Description of the spatio-temporal behaviour of cluster E2. (a) Close map view of Hypo71 locations; (b) close map view of HypoDD locations; (c) projection of Hypo 71 locations on a N30 segment; (d) projection of HypoDD locations on a N30 segment and (e) Distribution of magnitudes as a function of time. Plain red line is the cumulative number of events.

Figure S12. Description of the spatio-temporal behaviour of cluster E3. (a) Close map view of Hypo71 locations; (b) close map view of HypoDD locations; (c) projection of Hypo 71 locations on a $\mathrm{N} 30^{\circ}$ segment; (d) projection of HypoDD locations on a N30 segment and (e) Distribution of magnitudes as a function of time. Plain red line is the cumulative number of events.

Figure S13. Description of the spatio-temporal behaviour of cluster E4. (a) Close map view of Hypo71 locations; (b) close map view of HypoDD locations; (c) projection of Hypo 71 locations on a $\mathrm{N} 30^{\circ}$ segment; (d) projection of HypoDD locations on a N30 segment 
and (e) distribution of magnitudes as a function of time. Plain red line is the cumulative number of events.

Figure S14. Seismic coupling grids in far western Nepal confronted to the distribution of microseismicity. Blue and white triangles are permanent and temporary seismic stations, respectively. Size and colour of hypocentres depend respectively on magnitude and focal depth. Orange and red triangles are GNSS and GPS stations, respectively. Main thrust faults and tectonic features are represented: the Main Frontal Thrust as a bold red line and secondary thrusts faults as black lines upfront. Surface traces of normal faulting from Nakata (1984) are represented as bold purple lines. Red dashed lines correspond to the uncertainties on the lock/creep transition from Lindsey et al. (2018). Seismic coupling grids from (a) to (b) Jouanne et al. 2017 with or without taking into account the deformation partitioning from the Karakorum (WFNS) fault, respectively; (c) Stevens \& Avouac 2015 and (d) Dal Zilio et al. 2020.

Figure S15. Top panel: cumulative number of events for HiKnet (blue) and RSC (red) networks. The temporal distribution of magnitudes during HiKNet experiment is represented in the background. Bottom panel: cumulative seismic moment over time. Background dots represent the seismic moment inferred from the value of the moment magnitude of each event (Fig. S3).

Table S1. Stations description from HiKNet and RSC network.

Table-S2. Table showing source parameters of FPFIT solutions and associated errors ( $\mathrm{Fj}$ : misfit, polarities coherency in regards to the best fit focal solution; Nobs: number of polarities used for the fit; ANT: mean data weight used in the solution; STDR: station distribution ratio varying from 0 to 1 as a function of sourcestation distance; $\Delta$ STR: Azimuth error $\left(\right.$ degrees $\left.^{\circ}\right) ; \Delta$ Dip: Dip error $\left(\right.$ degrees $\left.^{\circ}\right) ; \Delta$ Rake: Rake error $\left(\right.$ degrees $\left.^{\circ}\right)$.

Table-S3. Hypo 71 catalogue of absolute locations.

Table-S4. HypoDD catalogue of relative locations.

Please note: Oxford University Press is not responsible for the content or functionality of any supporting materials supplied by the authors. Any queries (other than missing material) should be directed to the corresponding author for the paper. 